\title{
Evaluation of criteria for species delimitation of bagworm moths (Lepidoptera: Psychidae)
}

\author{
Veronica CHEVASCO ${ }^{1}$, Jelmer A. ElZINGA ${ }^{1}$, Johanna MAPPES ${ }^{2}$ and Alessandro GRAPPUTO ${ }^{3}$ \\ ${ }^{1}$ Department of Biological and Environmental Science, P.O. Box 35, FI-40014 University of Jyväskylä, Finland; \\ e-mails: vchevasco@gmail.com; jelmer.elzinga@jyu.fi \\ ${ }^{2}$ Center of Excellence in Biological Interactions, P.O. Box 35, FI-40014 University of Jyväskylä, Finland; \\ e-mail: johanna.r.mappes@jyu.fi \\ ${ }^{3}$ Department of Biology, University of Padova, Via Ugo Bassi 58/B, I-35121 Padova, Italy; e-mail: alessandro.grapputo@unipd.it
}

Key words. Lepidoptera, Psychidae, Dahlica, Siederia, DNA barcoding, COI

\begin{abstract}
Accurate identification of species is fundamental for biological research and necessary for species conservation. DNA barcoding is particularly useful when identification using morphological characteristics is laborious and/or unreliable. However, barcodes for species are dependent on the availability of reference sequences from correctly identified specimens. The traditional use of morphology to delimit the species boundaries of Finnish bagworm moths (Lepidoptera: Psychidae: Naryciinae: Dahliciini) is controversial because there is overlap in their morphological characteristics. In addition, there are no suitable molecular markers. We verified the delimitation of seven out of eight previously described taxa, by using the currently standardized COI barcode and phylogenetic inference based on fragments of mitochondrial (COI) and nuclear genes (MDH). Moreover, we compared the results of molecular methods with the outcome of geometric morphometrics. Based on molecular identification, our findings indicate that there are five sexual species (Dahlica and Siederia spp.) and two parthenogenetic species (D. fennicella and D. triquetrella) in Finland. We suggest that molecular methods, together with geometric morphometrics of male genitalia are an effective way of delimiting species of bagworm moths.
\end{abstract}

\section{INTRODUCTION}

Currently DNA barcoding (Hebert et al., 2003) is widely used for delimiting species, especially those of arthropods (Taylor \& Harris, 2012). The standard gene fragment used for DNA barcoding is the mitochondrial cytochrome oxidase I (COI) (Hebert et al., 2003). COI is suitable for DNA barcoding because it is a relatively large fragment (650-658 bp), which increases the likelihood that it will be possible to use to delimit species (Pradeep Kumar et al., 2012; Yang et al., 2012; Pérez-Losada et al., 2012). Partial sequences of mitochondrial cytochrome oxidase I are widely used for identifying many species that are difficult to differentiate using morphological characters, specially larval stages in Lepidoptera (Gossner \& Hausmann, 2009), arachnids (Barrett \& Hebert, 2005), and those species with complex life cycles (Foottit et al., 2009).

In this paper, we focus on Finnish bagworm moths of the tribe Dahliciini (Lepidoptera: Psychidae: Naryciinae). Their common name (bagworm moths) refers to the fact that their larvae construct cases of forest debris in which they live and complete their development (Rhainds et al., 2009). The tribe Dahliciini includes the genera Dahlica and Siederia (Bengtsson et al., 2008). According to Sobczyk (2011) the genus Dahlica includes 46 described species all of which have a Palaeartic distribution. On the other hand, the genus Siederia has a Palaearctic and Nearctic distribution and includes 17 described species. In Finland, there are five species in the genus Dahlica: D. charlottae (Meier, 1957), D. fennicella (Suomalainen, 1980), D. lazuri (Clerck, 1759), D. lichenella (Linnaeus, 1761 ) and $D$. triquetrella (Hübner, 1813), and three species in the genus Siederia: S. listerella (Linnaeus, 1758), S. rupicolella (Sauter, 1954) and S. cembrella (Linnaeus, 1761).

Delimiting the species of some bagworm moths is extremely difficult using traditional taxonomy because many species look remarkably alike and share similar ecological characteristics. For nearly three decades (Suomalainen, 1970, 1980; Pro Natura, 1997) the morphological identification of males of species belonging to the genera Dahlica and Siederia was based on qualitative analyses of the shape of their wing scales, genital index and the mid-tibial epiphysis. The morphological identification of females is more difficult because they lack wings. Therefore, features of the capito-prosternal plate and spines of pupae are the only characteristics that can be used for identifying the females of these species. Our observations indicate that overlapping morphological traits and absence of unique features makes the identification of species of bagworm moths extremely difficult. In addition, unresolved phylogenetic relationships and the lack of type specimens also hamper the use of traditional identification methods. In the most recent attempt using mitochondrial DNA, Grapputo et al. (2005) were unable to completely resolve the phylogenetic relationships due to weak phylogenetic support and lack of correspondence between molecular and morphological methods. Therefore, bagworm moths are good candidates for attempting 
to identify species using DNA barcoding, since morphological differentiation is minimal (Strutzenberger et al., 2011) and their taxonomy is not optimally resolved (Suomalainen, 1980; Palmqvist, 2008).

Bagworm moths are an interesting group of Lepidoptera because parthenogenetic and sexually reproducing species coexist (Kumpulainen et al., 2004; Elzinga et al., 2011b). Parthenogenetic reproduction is extremely rare in Lepidoptera but parthenogenetic species of bagworm moths are abundant wherever they occur. The existence of parthenogenetic species contradicts the notion that sexual reproduction carries greater benefits, such as the production of genetic variability and the elimination of deleterious mutations (Muller, 1964; Birky, 1999; Rice \& Friberg, 2009). Consequently, in order to test hypotheses about the origin (Chevasco et al., 2013) and maintenance (Elzinga et al., 2011b; Chevasco et al., 2012) of parthenogenetic reproduction it is essential to be able to correctly identify the sexual and parthenogenetic species of bagworm moths.

Here, we examine the parthenogens $D$. fennicella and $D$. triquetrella and the following sexual species: D. charlottae, D. lazuri, D. lichenella, S. listerella and S. rupicolella, but not $S$. cembrella as it, was not present at the sites we sampled. However, according to Sobczyk (2011) $S$. cembrella might be a junior subjective synonym of $S$. listerella or a southern subspecies of $S$. pineti. Previous molecular identification of bagworm moths (Elzinga et al., 2011a, b; Chevasco et al., 2012) was done using a fragment of the COII gene, including reference sequences published by Grapputo et al. (2005).

We aim to establish whether DNA barcoding based on a fragment of the COI gene gives similar results in terms of species identification to using the partial sequence of COII. In addition, in order to rule out any discrepancies, the outcome of DNA barcoding will be compared with the results of a phylogenetic analysis using the mitochondrial COI and nuclear MDH. Lastly, we will contrast the effectiveness of geometric morphometrics with the findings of molecular methods. Specifically, we will determine whether morphological characters are useful for delimiting species.

\section{MATERIAL AND METHODS}

\section{Sample collection}

In early March from 2007 to 2011, last instar larvae were collected by placing tape traps around tree trunks in Finland and Estonia. The details of the sites sampled, coordinates, species and numbers of individuals collected are summarized in the supplementary information (Table S1). All the individuals were reared under laboratory conditions until the adults emerged. For details see Elzinga et al. (2011b). Males and females used for morphological analyses were preserved in $99 \%$ ETOH. The analysis of male genitalia included data obtained from some additional pinned specimens collected in 2010 .

\section{Amplification of mitochondrial cytochrome oxidase I and II (COI-COII) and nuclear malate dehydrogenase gene (MDH)}

We used the traditional COI fragment for DNA barcodes (Wilson, 2012) and a smaller fragment of COII. The use of short
DNA fragments (this study), single nucleotide polymorphisms (SNP's) or insertions/deletions (indels) is recognized as DNA barcoding sensu lato (Valentini et al., 2009). Since mtDNA is maternally transmitted, we included a fragment of a nuclear gene $(\mathrm{MDH})$ in order to rule out hybridization between bagworm moths.

DNA was extracted from sexual and parthenogenetic individuals using the QIAGEN DNeasy Blood \& Tissue kit (QIAGEN, Hilden, Germany) according to the manufacturer's protocol and by eluting the DNA in $100 \mu \mathrm{l}$ of buffer AE. We amplified a $657 \mathrm{bp}$ fragment of the COI gene (GenBank accession numbers: JX307864-JX307990) using the primer pair reported in Wahlberg \& Wheat (2008): LCO (fwd) G GTC AAC AAA TCA TAA AGA TAT TGG and HCO(rev) T AAA CTT CAG GGT GAC CAA AAA ATC A. The COII gene fragment of 331 bp (GenBank accession numbers: JX308108- JX308217) was amplified using the primer pair: COII-M1F (fwd) TT GGA TTT AAA CCC CAT YTA and C2-N-3389(rev) TCA TAA GTT CAR TAT CAT TG (Simon et al., 1994). We also amplified a fragment of $730 \mathrm{bp}$ of the MDH gene (GenBank accession numbers JX307991-JX308043 and KC357571- KC357586) using the primer pairs MDHF(fwd) G AYA TNG CNC CNA TGA TGG GNG T and MDHr(rev) AGN CCY TCN ACD ATY TTC CAY TT (Wahlberg \& Wheat, 2008). The primer pairs for all gene fragments had an M13 "tail" either forward 5'TTGTAAAACGACGGCCAGT-3, or reverse 5'CAGGAAACAGCTATGACC-3'.

All PCR reactions were performed using the FailSafe PCR System (Epicentre Biotechnologies, Madison, Wisconsin) in a total reaction volume of $20 \mu \mathrm{l}$ that included 20-50 ng of DNA, $0.5 \mu \mathrm{M}$ of forward and reverse primer, $10 \mu \mathrm{l}$ of Buffer B $2 \mathrm{X}$ and $2.5 \mathrm{U} / \mu 1$ of Taq DNA Polymerase. Reaction conditions were as follows: an initial denaturation step of $30 \mathrm{~s}$ at $95^{\circ} \mathrm{C}, 30$ cycles consisting of $30 \mathrm{~s}$ at $95^{\circ} \mathrm{C}, 30 \mathrm{~s}$ at $50^{\circ} \mathrm{C}$ annealing temperature and $1.5 \mathrm{~min}$ at $72^{\circ} \mathrm{C}$ followed by one cycle of $5 \mathrm{~min}$ at $72^{\circ} \mathrm{C}$. The PCR products were verified by electrophoresis in agarose gel $(1 \%)$. If there was a single band, the products were purified using Exonuclease I-Shrimp Alkaline Phosphatase (Amersham Biosciences). If more bands were visualized, the expected product was cut from the gel and purified using the QIAquick gel extraction kit from QIAGEN according to the manufacturer's instructions. All sequencing reactions were conducted with the BigDye ${ }^{\circledR}$ Terminator v3.1, Cycle Sequencing Kit (Applied Biosystems) using the M13 primers $(0.2 \mu \mathrm{M})$ and run on an ABI 3130xl Genetic Analyzer (Applied Biosystems). The PCR products were sequenced for both strands and edited for ambiguities in Seqscape v2.6 (Applied Biosystems). Subsequently, the sequences were aligned with ClustalW in MEGA v. 5 (Tamura et al., 2011) with default settings.

\section{DNA analyses}

DNA barcoding

The NJ trees, for the COI and COII, were based on the Kimura 2 parameter (K2P) model of nucleotide substitution (Kimura, 1980) as recommended in the barcoding protocol (Ratnasingham \& Hebert, 2007). The K2P is the most commonly used and widely accepted substitution model for DNA barcoding (Park et al., 2011; Ruiz-Lopez et al., 2012; Jin et al., 2013). Nevertheless, its applicability is under debate. According to Srivathsan \& Meier (2012) the model did not appear to increase identification success and might not be entirely suitable for closely related COI sequences.

Trees were obtained using MEGA v. 5 (Tamura et al., 2011). The delimitation of the different species of bagworm moths was made according to their clustering with the reference sequences. We used Genbank vouchers for COII from Grapputo et al. 

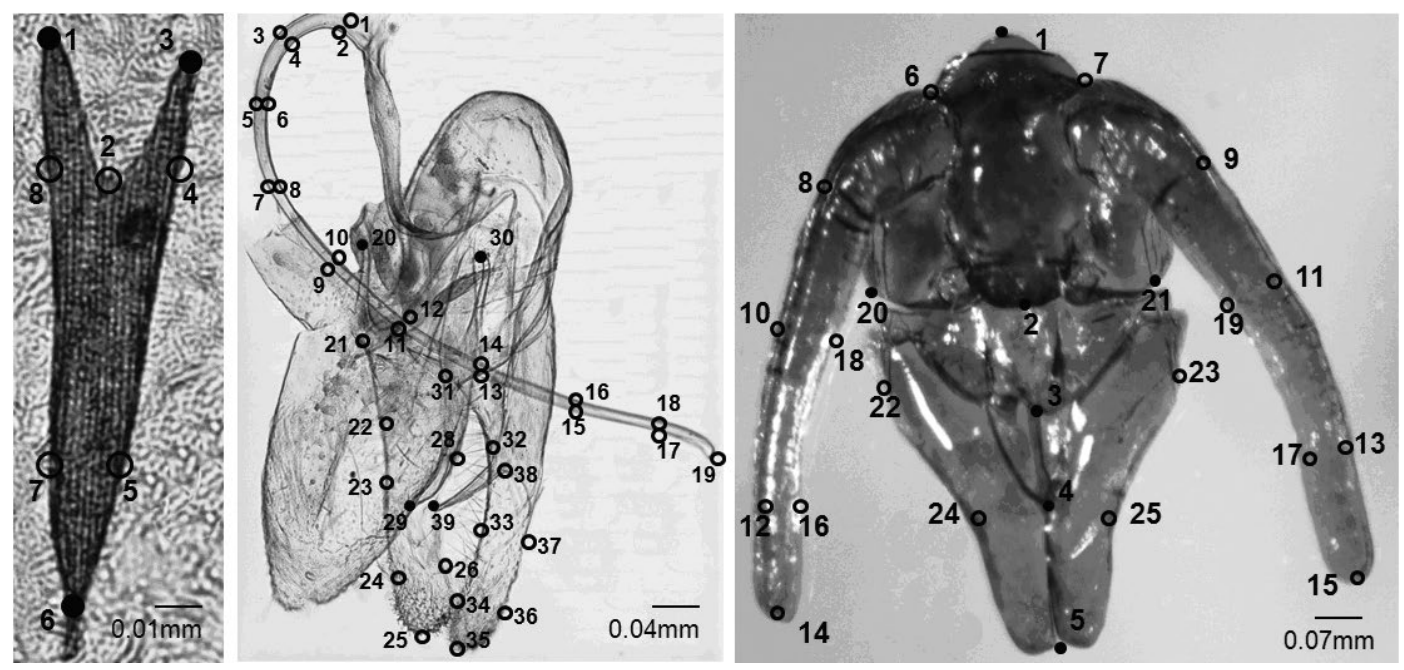

Fig. 1. Representation of landmarks (black circles) and semi-landmarks (open circles) used in the geometric morphometric analyses of seven species of Naryciinae. (1) Wing scale (set of eight points) (2) Male genitalia (thirty-nine points) (3) capitoprosternal plate of female pupa (set of twenty-five points).

(2005). Therefore, the species names reported in this study follow this reference. Additionally, the inter-specific and intraspecific nucleotide sequence divergence was calculated for $\mathrm{COI}$ and COII fragments using the K2P model as recommended by Hebert et al. (2003). Further details are found in the supplementary information.

The species specific DNA barcodes were submitted to GenBank (accession numbers JX307864-JX307947) and compared with the barcodes available in the Barcode of Life Database (BOLD) (http://www.boldsystems.org).

Usefulness of the mitochondrial cytochrome oxidase I and II (COI-COII)

We used an identification approach based on direct sequence comparison to compare our results with those of the NJ trees using TaxonDNA/SpeciesIdentifier 1.7.7-dev3 (Meier et al., 2006). The COI and COII sequences were evaluated using the following criteria: "Best Close Match" and "All species barcodes." The threshold similarity value for all comparisons was computed from pairwise distances. "Best Close Match" identifies the best barcode match of a sequence and assigns a species name to a query only if the barcode is sufficiently similar. In contrast, "All species barcodes" is more rigorous than the "Best Close Match" criterion as it uses information from all conspecific barcodes in the data instead of focusing on those barcodes that are similar to the query.

DNA barcoding profiles based on different distance thresholds

We tested whether the distance thresholds proposed for DNA barcoding, such as 1\% (Ratnasingham \& Hebert, 2007) and 3\% (Hebert et al., 2003) grouped species of moths in the same clusters as those in the NJ trees. We conducted the clustering analysis using TaxonDNA/SpeciesIdentifier 1.7.7-dev3 (Meier et al., 2006). Additionally, we used the Barcode Index Number (BIN) (Ratnasingham \& Hebert, 2013) to estimate the number of species.

The Barcode Index Number (http://www.barcodinglife.org/ index.php/Public BarcodeIndexNumber Home) clusters barcode sequences based on an algorithm that works on the basis of a 2\% distance cut-off (Smith et al., 2012). The BIN clusters were obtained directly from our GenBank barcode records, which are also available in BOLD.

\section{Phylogenetic relationships}

DNA barcodes alone provide insufficient information about taxa (Rubinoff \& Holland, 2005). Therefore, this analysis was performed to determine whether the species specific clusters were similar to those of the NJ trees, which are based on pairwise distance differences.

The best-fit models for nucleotide substitution were obtained using jModelTest v 2.1.1 (Darriba et al., 2012) applying the Akaike information criterion (AIC) (Posada \& Crandall, 1998). For the mitochondrial COI fragment we obtained the general time reversible model (Lanave et al., 1984) with gamma distributed rate variation across sites $(\mathrm{GTR}+\Gamma)$. The best model for the MDH fragment was the symmetrical model (Zharkikh, 1994) with a proportion of invariable sites and gamma distributed rate variation across sites $(\mathrm{SYM}+\mathrm{I}+\Gamma)$. The sequences of Diplodoma laichartingella (Mutanen et al., 2010) GenBank accession numbers COI GU828726 and $M D H$ GU830429) and Narycia duplicella were included as outgroups. We did not obtain a PCR amplification product for the $M D H$ gene in $N$. duplicella.

We chose not to use the short COII fragment since it is not the standard barcoding gene. A previous study (Chevasco et al., 2013) on the same species of bagworm moths included a phylogenetic reconstruction of the COI and COII gene fragments. Moreover, the same paper reports a multi-gene phylogeny of four gene sections (COI-COII-CAD-MDH).

Bayesian phylogenetic trees, for the $\mathrm{COI}$ and $\mathrm{MDH}$, were obtained using MrBayes v 3.2 (Ronquist et al., 2012). Two simultaneous independent runs with three heated chains and one "cold" chain were run for a number of generations that varied between 800 thousand and 1.9 million, with a sample frequency of 1000 and a burnin of $25 \%$ of the total number of samples. In order to obtain a strict consensus tree, which shows only those relationships that are unambiguously supported by the data, we always used the contype = allcompat option. The default of a random starting tree was used at all times. The standard deviation of split frequencies $(\leq 0.01)$ and the potential scale reduction factor (near 1.00) were used as the parameters for convergence (Hall, 2011). The support for each cluster was evaluated following the criteria of Hillis-Bull (1993) where a Bayesian posterior probability (BPP) of $\geq 0.95$ is considered as significant support for the phylogenetic relationships. For the 
TABLE 1. Summary of interspecific pairwise sequence divergence for the NJ tree (K2P model, pairwise deletion) based on mitochondrial genes (COI-COII) of seven different species of bagworm moths, as shown in Figs S1 and S2.

\begin{tabular}{|c|c|c|c|c|c|c|c|c|c|c|c|c|c|c|c|}
\hline \multicolumn{16}{|c|}{ Pairwise inter-specific sequence divergence based on mtDNA } \\
\hline \multicolumn{8}{|c|}{ COI (657 bp) } & \multicolumn{8}{|c|}{ COII (331 bp) } \\
\hline & Dchar & Dfen & Dlaz & Dlich & Slist & Srupi & Dtriq & & Dchar & Dfen & Dlaz & Dlich & Slist & Srupi & Dtriq \\
\hline Dchar & & & & & & & & Dchar & & & & & & & \\
\hline Dfen & 0.041 & & & & & & & Dfen & 0.049 & & & & & & \\
\hline Dlaz & 0.038 & 0.009 & & & & & & Dlaz & 0.05 & 0.015 & & & & & \\
\hline Dlich & 0.048 & 0.032 & 0.031 & & & & & Dlich & 0.056 & 0.03 & 0.023 & & & & \\
\hline Slist & 0.047 & 0.052 & 0.052 & 0.063 & & & & Slist & 0.057 & 0.063 & 0.06 & 0.064 & & & \\
\hline Srupi & 0.044 & 0.046 & 0.039 & 0.047 & 0.051 & & & Srupi & 0.046 & 0.047 & 0.048 & 0.053 & 0.05 & & \\
\hline Dtriq & 0.044 & 0.056 & 0.053 & 0.057 & 0.062 & 0.056 & & Dtriq & 0.031 & 0.037 & 0.037 & 0.042 & 0.044 & 0.038 & \\
\hline
\end{tabular}

MDH gene fragment, the heterozygous sites were left with the nucleotide ambiguity code (unphased). Ambiguous characters were treated as uncertain in MrBayes as they do not carry any phylogenetic information.

\section{Male morphology}

Traditionally, the morphological identification of Dahlica and Siederia has been based on the genital index and a qualitative analysis of the shape of wing scales (Sauter, 1956; Dierl, 1966; Suomalainen, 1980; Pro Natura, 1997; Hauser, 2004; Bengtsson et al., 2008). However, in our analysis we used geometric morphometrics to characterize wing scales and genitalia in order to determine whether morphological characters distinguish the same taxonomical entities as molecular methods.

To examine the scales we mounted each right forewing on a microscope slide. Then, we took a photograph of the distal $3 / 4$ of each wing, between the R2 and R3 veins, with a $10 \times$ magnification on a Zeiss Axioskop microscope using the program SPOT $v$ 4.0.1 (Diagnostic Instruments, Sterling Heights, MI). Each scale was characterized by a set of homologous points that define its shape. The points that could be precisely identified were defined as landmarks (3) while the others (5) which were strategically spaced were considered as semi-landmarks (Fig. 1). For each individual we were only able to analyze five scales as the scales frequently overlapped, which prevented proper characterization.

In order to prepare microscope slides of the genitalia, the distal part of the abdomen was left overnight in a solution of $10 \% \mathrm{KOH}$ to soften the surrounding tissues. A day later, genitalia were dissected. As the genitalia of males are easily damaged; the genital structures were not separated but left in their original configuration. Since we wanted to avoid inconsistencies in geometric morphometric characterization, the genitalia were mounted in the same orientation in euparal (ANSCO Laboratories, Manchester, England). Subsequently, a photograph was taken using a Zeiss Axioskop microscope at a magnification of $40 \times$ using the program SPOT v 4.0.1 (Diagnostic Instruments, Sterling Heights, MI). The genitalia, were considered to be a single unit and, characterized by a set of homologous points on photographs that showed genital structures in the same orientation. A set of semi-landmarks, which were strategically spaced (19), described the phallus shape, whereas a set of landmarks (4) and semi-landmarks (16) characterized both valve (Fig. 1).

\section{Female morphology}

Traditional morphological identification of females is based on the shape of the capito-prosternal plate during the pupal stage (Suomalainen, 1980; Hättenschwiler, 1985; Pro Natura, 1997). Only Hauser (2004) suggests the use of an index based on the length of the pupal antennal sheath and the length of the capito- prosternal plate. To determine whether the pupal capitoprosternal plate is as useful as molecular methods for species delimitation we used a set of homologous points that describe its shape. First, the capito-prosternal plate of the female pupa was mounted dry on a microscope slide. Then, all points were located on a photograph that was taken using a stereomicroscope Olympus SZX9 at a magnification of $12.5 \times$ using the program Image Pro Plus v7.0 (MediaCybernetics, Silver Springs, MD). The points that could be precisely identified were defined as landmarks (7) while the rest, which were strategically spaced, were defined as semi-landmarks (18) (Fig. 1).

\section{Geometric morphometric analysis}

The landmark and semi-landmark digitations were performed on photographs using TPSUTIL v 1.53 (Rohlf, 2012) and TPSDIG v 2.16 (Rohlf, 2010). Subsequently, the data were imported to MorphoJ v $1.05 \mathrm{~d}$ (Klingenberg, 2011). Next, shape information was extracted from the landmarks and semilandmarks with a full Procrustes fit and projected onto the tangent space to the shape space (Dryden \& Mardia, 1998). Then, the new set of shape variables was examined by using canonical variate analysis (CVA), which is frequently used in morphometrics (Cardini, 2003; Debat et al., 2003; Klingenberg et al., 2003, 2012). CVA maximizes the differences between species, and is an efficient method for detecting the degree of separation between taxa (Klingenberg et al., 2012). However, it is important to note that CVA is based on an a priori sorting of the species.

The output of results in MorphoJ also includes matrices of pairwise Mahalanobis and Procrustes distances. According to Klingenberg \& Monteiro (2005) Mahalanobis distance reflects the degree of separation between groups, but does not consider the variation within groups. In contrast, Procrustes distance characterizes differences between pairs of shapes or deviations of individual shapes from the population average. Therefore, in accordance with our aims we focused on Mahalanobis distances and assessed the statistical significance using a permutation test with 10,000 iterations.

\section{RESULTS}

\section{DNA barcoding}

We amplified a partial sequence of the COII gene (331 bp) in which 42 sites were variable $(12.69 \%)$ and 40 sites $(12.08 \%)$ were parsimony informative. The partial sequence of the COI gene consisted of $657 \mathrm{bp}$ in which 115 sites were variable $(17.50 \%)$ and $79(12.02 \%)$ were parsimony informative. 
TABLE 2. Matching percentages (NA = not applicable) for species level comparison of COI sequences with sequence vouchers for barcodes in BOLD.

\begin{tabular}{lcc}
\hline & Species specific match & BOLD results \\
\hline D. triquetrella & $100 \%$ & \\
D. fennicella & NA & D. fennicella $100 \%$ / Dahlica sp. $98.78 \%-98.93 \%$ \\
D. lichenella & NA & Dahlica sp. $99.39 \%-100 \%$ D. lichenella $99.39 \%-99.85 \%$ \\
D. charlottae & NA & Dahlica sp. $100 \%-S$. pineti $99.02 \%-99.19 \%$ \\
D. lazuri & NA & Dahlica sp. $99.85 \%-D$. fennicella $99.08 \%$ \\
S. listerella & NA & S. listerella $99.85 \%-100 \% /$ D. lazuri $99.85 \%-100 \%$ \\
\hline
\end{tabular}

We conducted a preliminary classification of the species of bagworm moths included in this study based on a Neighbor Joining (NJ) tree for the COII fragment. On the COII NJ tree (Fig S1 - supplementary information) the new sequences clustered with those published by Grapputo et al. (2005) for the following parthenogenetic species: D. fennicella, $D$ triquetrella, and sexual species: $D$. lazuri, D. lichenella, S. rupicolella, D. charlottae, S. listerella. The topology of the NJ tree based on COI (Fig. $\mathrm{S} 2$ - supplementary information) is not the same as that based on COII. We obtained the same, but better supported species specific clusters in the COI tree. Details of the bootstrap consensus NJ trees are included in the supplementary information (Fig. S1).

The genetic distances (inter-specific and intra-specific) for both mitochondrial genes were calculated as the pairwise sequence divergence based on the K2P model (Table 1). The intra-specific distances for the COI and COII were less than $1 \%$ (not shown).

The species level comparisons of the COI sequences (this study) with the barcode records in BOLD (last accessed 30.06.2013) yielded a species level match only for the parthenogenetic $D$. triquetrella $(100 \%)$. The queries for $D$. fennicella, $D$. lichenella and $S$. listerella did not generate a species specific level match, but indicated that the sequences were likely to belong to those species (Table 2). Nevertheless, two sequences that we identified as D. lichenella (10-EVO-59-F, 08-EST-10-PU) matched those of other species. The sequence 10-EVO-59-F matched that of $D$. wehrlii $(99.39 \%$; sample ID TLMF Lep 01371) and $S$. pineti (99.39\%; sample ID CLV510712). In addition, 08-EST-10-PU matched that of D. klimeschi (100\%; samples IDs CLV3603; CLV24008; CLV1720; BC-EH-V95) and D. wehrlii (99.54\%; sample ID TLMF Lep 01371). None of the sequences we obtained for $D$. charlottae and D. lazuri generated a match in the BOLD records (Table 2). Lastly, the BOLD data base did not have any vouchers for the sequences that we designated $S$. rupicolella, except for our own twenty-three barcode records mined from GenBank (accession numbers JX307923-JX307925; JX307927JX307930; JX307975-JX307990). A species specific search for these sequences generated a match with that of D. lazuri (99.69\%-100\%; sample ID MM05439), with the exception of 08-TOIV-2-M which also matched that of $S$. meirella (98.62\%; sample ID STG173).

\section{Usefulness of mitochondrial cytochrome oxidase I and II}

Our results using Taxon DNA/Species Identifier 1.7.7-dev3 (Meier et al., 2006) revealed that the COII had high percentages of successful species identification. However, the COII had lower success when compared with the COI.

The percentages for the COII were computed using the pairwise distance summary $(4.53 \%)$. Based on "Best Close Match", $88.23 \%$ of the identifications were correct. Nevertheless, a $9.8 \%$ of the identifications were ambiguous and $1.96 \%$ incorrect. One sequence of $S$. rupicolella (07-KU-S710-L) was incorrectly matched and of uncertain identification. Another sequence of $S$. rupicolella (08-RH-14-F) was also uncertain, and so it could not be specifically identified. Of "All Species Barcodes" $76.47 \%$ were correctly, $21.56 \%$ ambiguously and $1.96 \%$ incorrectly identified. Ambiguous identifications were recorded for D. charlottae (07-LV5-20-1-F, 08-JS1-24-F, 09-JS1-56-F， 09-OV2-4-M，10-EVB-138-F， 10-EVC74-M, 10-EVE-117-F, 10-EVF-133-F and 10-EVO-76-F) and D. lazuri (07-POT-5-M, 08-MM-18-F). The only incorrect identification was for a sequence from $D$. charlottae (09-OV2-3-M).

The use of COI resulted in a higher identification success than COII. The identification percentages were computed using pairwise distance summary (1.21\%). This resulted in $98.95 \%$ of the samples being correctly identified based on "Best Close Match" and only $1.04 \%$ incorrectly identified, due to a single sequence of $S$. listerella (08-EST-1-L). Of "All Species Barcodes" 98.95\% were correctly, $0 \%$ ambiguously and $1.04 \%$ incorrectly identified, due to one sequence for S. listerella (09-HP4-19-F).

\section{DNA barcoding profiles based on different distance thresholds}

The distance threshold values of $3 \%$ recommended by Hebert et al. (2003) and 1\% by Ratnasingham \& Hebert (2007) did not generate the same number of clusters as the NJ trees. For instance, for the COII gene, the threshold value of $3 \%$ (maximum pairwise distance of $3.32 \%$ ) resulted in four clusters with only one species specific cluster for $S$. listerella showing a maximum pairwise distance of $0.60 \%$. When the threshold value was reduced to $1 \%$ (maximum pairwise distance of $1.51 \%$ ) the analysis generated seven clusters with five species specific groups (for $S$. listerella, D. lazuri, D. triquetrella, D. fennicella and D. lichenella). Maximum pairwise dis- 


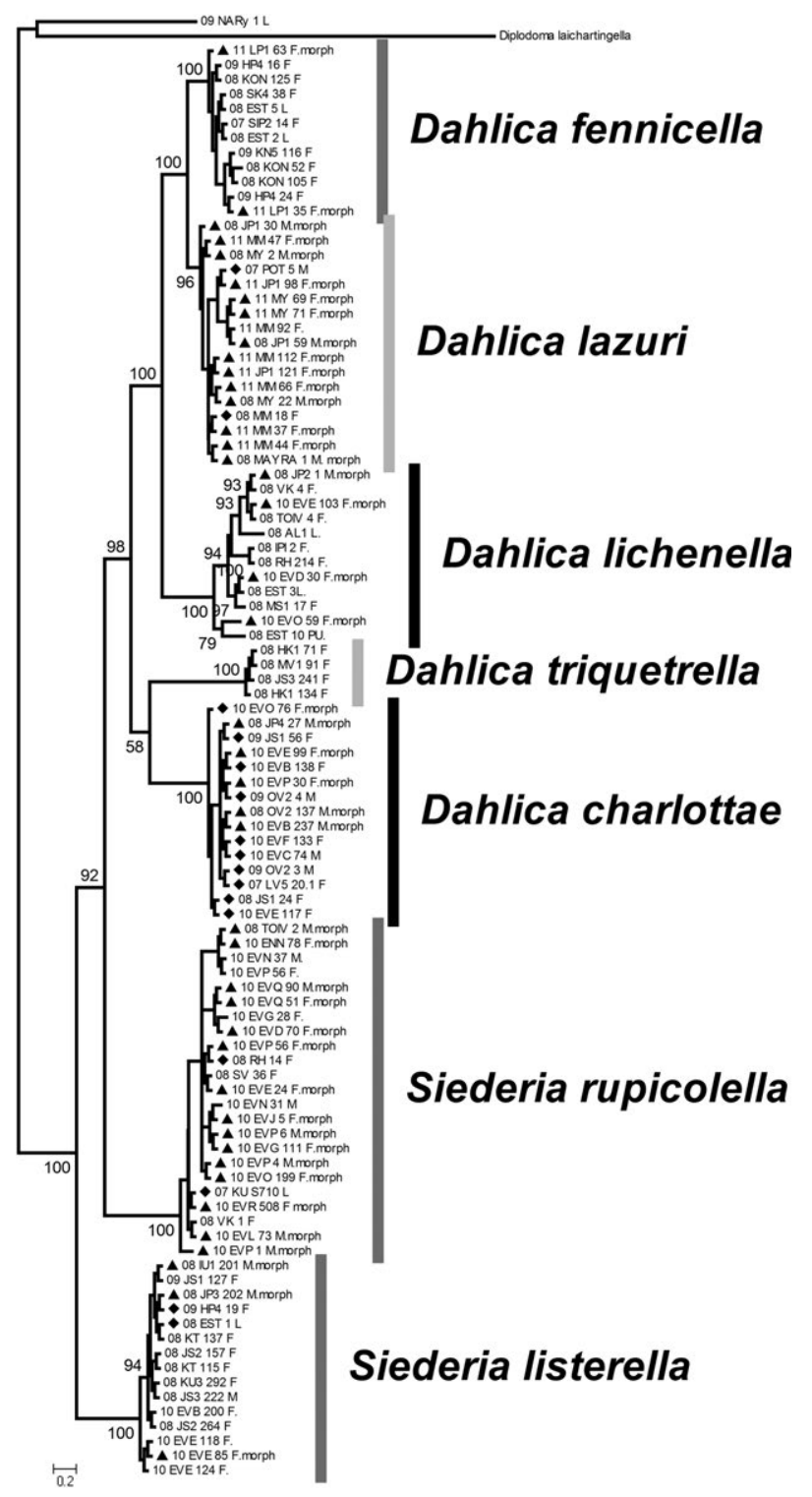

Fig. 2. Phylogeny of Dahlica and Siederia species based on a partial sequence of the mitochondrial gene COI estimated using Bayesian Inference and the GTR $+\Gamma$ model of nucleotide substitution. Species names follow those reported in Grapputo et al. (2005). The Bayesian posterior probabilities are shown at the nodes of the tree. The outgroups are $N$. duplicella (09-NARy1-L) and D. laichartingella (Diplod.). The specimens included in the morphological analysis have the morph abbreviation (black triangle). Samples for which the identification by Taxon/DNA Species Identifier was ambiguous / incorrect are indicated by a black diamond. The scale bar at the bottom of the tree indicates the $\%$ of divergence.

tances for these taxa were $0.6 \%, 0 \%, 0 \%, 0.3 \%$ and $1.51 \%$, respectively.

Distance threshold clustering generated more clusters using the COI gene than the COII gene. The threshold value of $3 \%$ produced five groups with a $3.50 \%$ maximum pairwise distance, but only three species specific clusters for $S$. rupicolella, D. triquetrella, and D. charlottae with a maximum pairwise distance of $0.45 \%$, $0 \%$ and $0 \%$ respectively. Comparatively, eight clusters

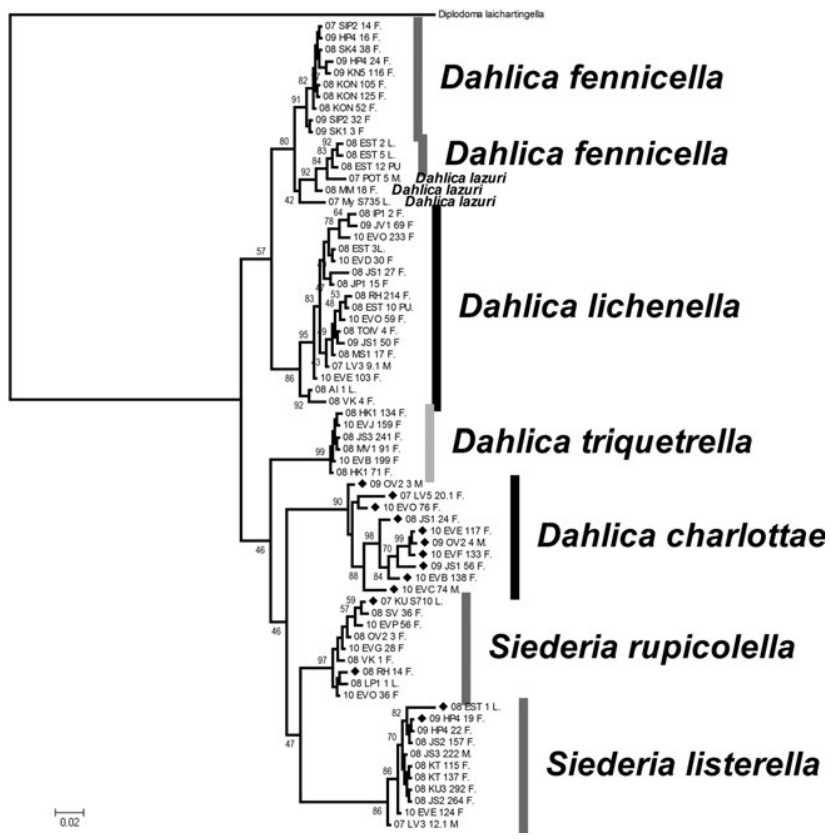

Fig. 3. Phylogeny of Dahlica and Siederia species based on a partial sequence of the nuclear gene MDH estimated using Bayesian Inference and the SYM $+\mathrm{I}+\Gamma$ model of nucleotide substitution. Species names follow those reported in Grapputo et al. (2005). The Bayesian posterior probabilities are shown at the nodes of the tree and D. laichartingella (Diplod.) is the outgroup. Samples for which the identification by Taxon/DNA Species Identifier was ambiguous / incorrect are indicated by a black diamond. The scale bar at the bottom of the tree indicates the $\%$ of divergence.

were generated with a threshold value of $1 \%$ with a maximum pairwise distance of $1.21 \%$. However, only $D$. charlottae, D. triquetrella and S. rupicolella were included in species specific clusters with a maximum pairwise distance of $0 \%, 0 \%$ and $0.45 \%$, respectively.

The BOLD Barcode Index Number (BIN) generated six clusters of species: BIN85842 (D. fennicella-D. lazuri); BIN31523 (D. lichenella); BIN31525 (S. rupicolella); BIN496397 (D. triquetrella); BIN85841 (D. charlottae) and BIN85840 (S. listerella). For details see Fig. S2 supplementary information.

\section{Phylogenetic relationships-Bayesian inference}

Independent phylogenetic trees were obtained based on mitochondrial (COI) and nuclear (MDH) gene fragments. The MDH was $730 \mathrm{bp}$ long, with 121 (16.57\%) variable sites and $111(15.21 \%)$ parsimony informative sites.

Overall, the phylogenetic trees based on $\mathrm{COI}$ and $\mathrm{MDH}$ are broadly similar in topology and have the same species specific clusters as those of the bootstrap NJ consensus trees. Species specific clusters are strongly supported in the COI tree. In contrast, in the MDH tree there is weaker support for these clusters and the parthenogenetic $D$. fennicella and sexual $D$. lazuri are paraphyletic. In addition, the samples that were ambiguously/incorrectly identified by Taxon/DNA Species Identifier clustered within the same species specific clusters as in the NJ trees (Figs 


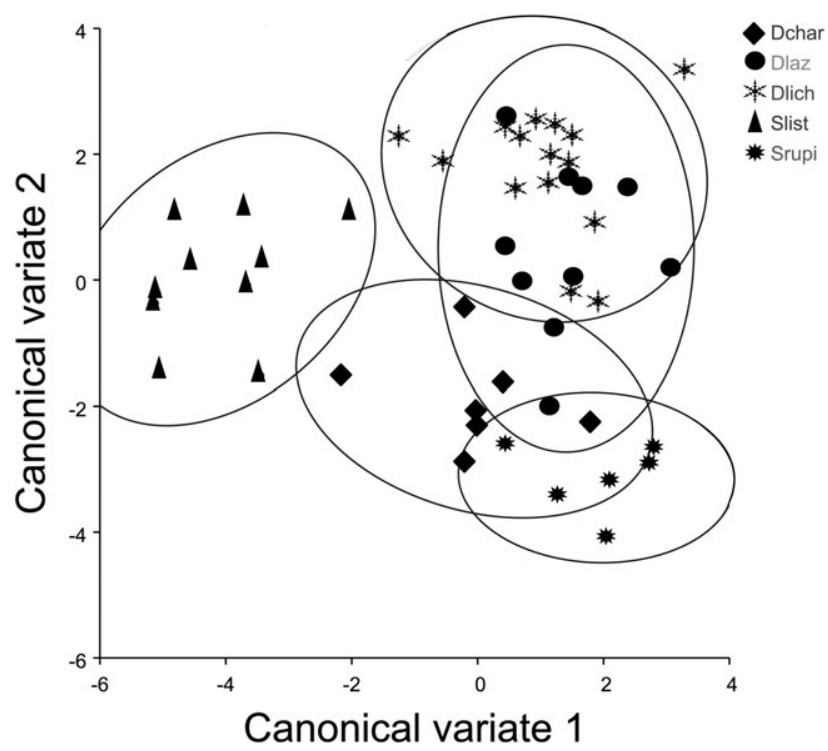

Fig. 4. Plot of wing scale data for five species of Dahlica and Siederia $($ Dchar $=D$. charlottae, Dlaz $=D$. lazuri, Dlich $=D$. lichenella, Slist $=S$. listerella and Srupi $=S$. rupicolella ) based on the first two canonical variates of the CVA. All the species are highlighted by their $95 \%$ confidence ellipses.

S1-S2, Figs 2-3). A detailed description of the trees is as follows:

\section{Mitochondrial cytochrome oxidase I (COI)}

We did not find any support for the monophyly of Siederia (Fig 2). The common ancestry of the sexuals $D$. lichenella, D. lazuri and parthenogenetic D. fennicella was strongly supported (1 BPP-Bayesian Posterior Probability). Within this cluster, the sister species status of the parthenogenetic $D$. fennicella and sexual $D$. lazuri is well supported (1 BPP).

This phylogenetic reconstruction did not recover good support for the sister species status of the parthenogenetic D. triquetrella and D. charlottae (0.58 BPP). Siederia listerella occupies a basal position in relation to the other species. In contrast, $S$. rupicolella shares a common ancestor (0.92 BPP) with species of the genus Dahlica.

COII was not used because a concatenated mtDNA tree, which included both COI and COII gene fragments (Chevasco et al., 2013), recovered the same topology as COI.

\section{Malate dehydrogenase (MDH)}

In amplifying the MDH gene we were unable to obtain a PCR product for $N$. duplicella. Therefore, we included a sequence for D. laichartingella as the outgroup. We did not find any support for the monophyly of Dahlica or Siederia. As for COI, D. fennicella, D. lazuri and D. lichenella were recovered as a monophyletic group, although it is not well supported (0.57 BPP). Within this group, the Finnish D. fennicella formed a separate cluster $(0.91$ BPP) from the Estonian D. fennicella (0.84 BPP) and

TABle 3 Mahalanobis distances for $\widehat{\delta}$ wing scales $(D$. charlottae $\mathrm{n}=7 ;$ D. lazuri $\mathrm{n}=10 ;$ D. lichenella $\mathrm{n}=15 ;$ S. listerella $\mathrm{n}=10$; $S$. rupicolella $\mathrm{n}=6)$ ô genitalia $(D$. charlottae $\mathrm{n}=11 ; D$. lazuri $\mathrm{n}=10 ; D$. lichenella $\mathrm{n}=14 ; S$. listerella $\mathrm{n}=11 ; S$. rupicolella $\mathrm{n}=$ 9 ) and + capito prosternal plate $(D$. charlottae $\mathrm{n}=10 ;$. fennicella $\mathrm{n}=10 ; D$. lazuri $\mathrm{n}=8$; D. lichenella $\mathrm{n}=9 ;$. triquetrella $\mathrm{n}=$ 6 S. listerella $\mathrm{n}=6 ;$ S. rupicolella $\mathrm{n}=8)$. Statistically significant $(\mathrm{P}<0.0001)$ values are indicated in bold.

\begin{tabular}{|c|c|c|c|c|c|c|}
\hline \multicolumn{7}{|l|}{ đWing scales } \\
\hline & D. charlottae & D. lazuri & D. lichenella & S. listerella & & \\
\hline D. lazuri & 4.5874 & & & & & \\
\hline D. lichenella & 4.5773 & 3.7629 & & & & \\
\hline S. listerella & 5.3316 & 5.9631 & 5.6255 & & & \\
\hline S. rupicolella & 4.6770 & 5.0914 & 5.2771 & 6.9226 & & \\
\hline \multicolumn{7}{|l|}{ ot Genitalia } \\
\hline & D. charlottae & D. lazuri & D. lichenella & S. listerella & & \\
\hline D. lazuri & 11.3701 & & & & & \\
\hline D. lichenella & 10.2163 & 4.3673 & & & & \\
\hline S. listerella & 12.3932 & 15.1744 & 13.5477 & & & \\
\hline S. rupicolella & 14.6768 & 16.8405 & 16.0543 & 12.7102 & & \\
\hline \multicolumn{7}{|c|}{ \& Capito-prosternal plate } \\
\hline & D. charlottae & D. lazuri & D. lichenella & S. listerella & S. rupicolella & D. fennicella \\
\hline D. lazuri & 24.6599 & & & & & \\
\hline D. lichenella & 15.4740 & 12.4223 & & & & \\
\hline S. listerella & 20.9898 & 11.9116 & 9.7544 & & & \\
\hline S. rupicolella & 14.2958 & 16.4893 & 7.7018 & 11.4961 & & \\
\hline D. fennicella & 16.4080 & 12.1879 & 6.4375 & 11.7921 & 9.2925 & \\
\hline D. triquetrella & 23.3389 & 31.4765 & 27.5951 & 30.4355 & 27.5016 & 29.4094 \\
\hline
\end{tabular}




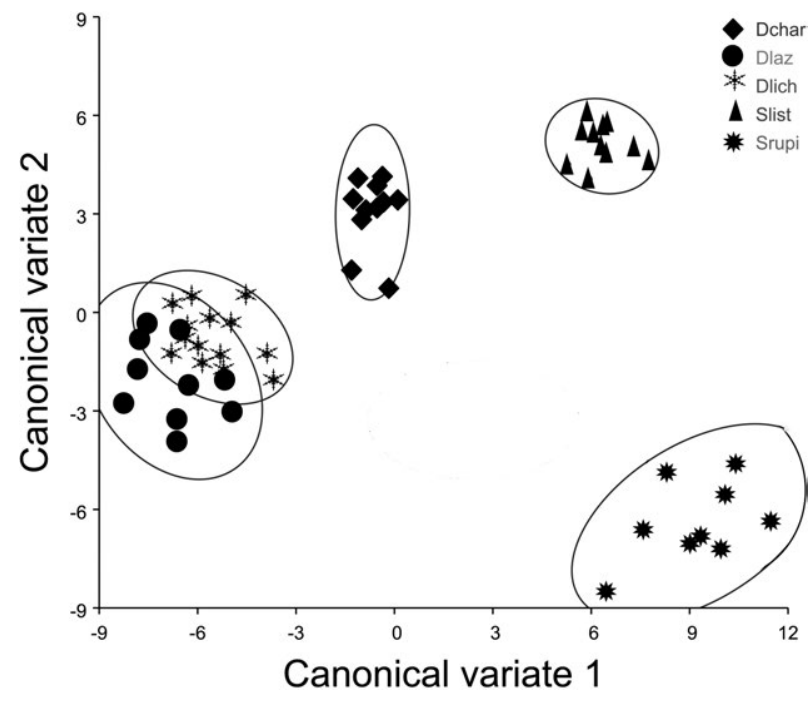

Fig. 5. Plot of male genitalia data for five species of Dahlica and Siederia $($ Dchar $=D$. charlottae, Dlaz $=D$. lazuri, Dlich $=$ D. lichenella, Slist $=S$. listerella and Srupi $=S$. rupicolella $)$ based on the first two canonical variates of the CVA. All the species are highlighted by their $95 \%$ confidence ellipses.

both clustered (0.80 BPP) with the Finnish $D$. lazuri. The parthenogenetic $D$. triquetrella is located in a basal position in relation to $D$. charlottae and the species of the genus Siederia. Species of the genus Siederia are sister species but lack support (0.47 BPP).

A multi-gene phylogeny was not reconstructed based on earlier results (Chevasco et al., 2013). The previously reported phylogenetic tree, which is based on four gene fragments (COI-COII-CAD-MDH), has a broadly similar topology to the MDH tree.

\section{Morphological analyses of males}

Wing scales

The canonical variate analysis (CVA) of five groups of species revealed four canonical variates of which the first two accounted for $72 \%$ of the variation. According to the first two canonical variates, $S$. listerella, $S$. rupicolella and $D$. lichenella are clearly separated (Fig. 4). The differences in the other taxa were not distinguished by the first two canonical variates. Nevertheless, possible differentiation was further resolved by Mahalanobis distances, which ranged from 3.76 (D. lazuri vs. D. lichenella) to 6.92 (S. listerella vs. S. rupicolella). The permutation tests indicate that the mean shape of the scales differs significantly $(\mathrm{P}<0.0001$ in pairwise permutation tests $)$ (Table 3) between the following pairs of species: $D$. charlottae-D. lichenella, D. charlottae-S. listerella, D. lazuri-D. lichenella, D. lazuri-S. listerella, $D$. lichenella-S. listerella, D. lichenella-S. rupicolella and $S$. listerella-S. rupicolella. The Procrustes distances ranged from 0.1254 (D. lazuri vs. S. rupicolella) to $0.2877 \mathrm{D}$. charlottae vs. D. lichenella).

\section{Genitalia}

CVA of the genitalia based on results for five groups of species revealed four canonical variates, of which the first

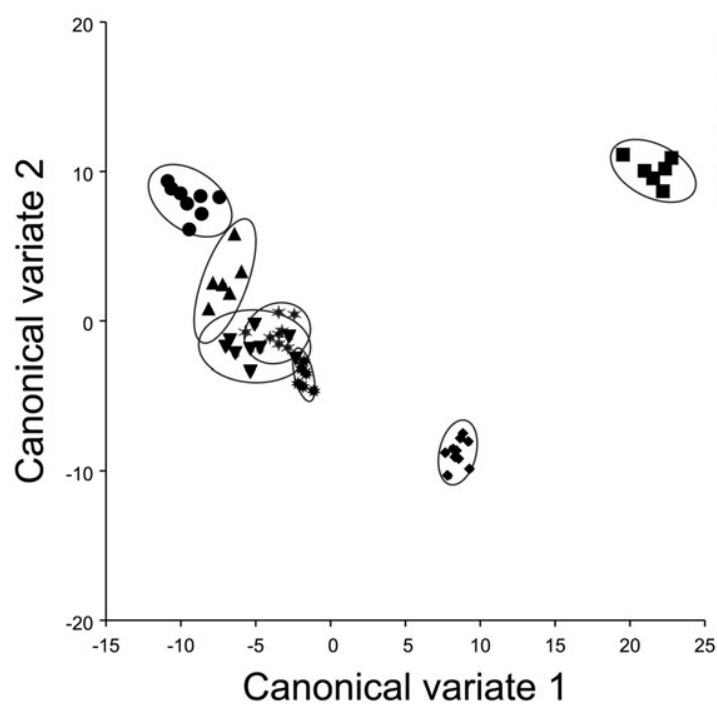

Fig. 6. Plot of the data for the capito-prosternal plate of female pupae for seven species of Dahlica and Siederia (Dchar $=D$. charlottae, Dfenni $=D$. fenicella, Dlaz $=D$. lazuri, Dlich $=$ $D$. lichenella, Dtriq $=D$. triquetrella, Slist $=S$. listerella and Srupi $=S$. rupicolella) based on the first two canonical variates of the CVA. All the species are highlighted by their $95 \%$ confidence ellipses.

two accounted for $79 \%$ of the variation. The plot of the first two canonical variates (Fig. 5) indicates that $D$. charlottae, S. listerella and $S$. rupicolella are clearly distinct from each other. As for the wing scales, the differences between the species were better resolved based on Mahalanobis distances, which ranged from 4.37 (D. lazuri vs. D. lichenella) to 16.84 (D. lazuri vs. S. rupicolella). The permutation tests indicate that the mean shape of the genitalia differs significantly between the species (all $\mathrm{P}<0.0001$ in pairwise permutation tests) (Table 3). The Procrustes distances ranged from 0.0811 (D. lazuri vs. D. lichenella) to 0.2780 (D. lazuri vs. S. listerella).

\section{Morphological analyses of females (capito-prosternal plate)}

Our CVA of female morphology based on the results for seven groups of species revealed six canonical variates of which the first two accounted for $86 \%$ of the variation. According to the first two canonical variates, $D$. triquetrella, D. charlottae, S. listerella and D. lazuri are clearly separated from one another (Fig. 6). In order to obtain a better differentiation between the species, we used Mahalanobis distances, which ranged from 6.44 ( $D$. fennicella vs. D. lichenella) to 31.48 (D. lazuri vs. D. triquetrella). The permutation tests indicate that the mean shape of the capito-prosternal plate differed significantly ( $\mathrm{P}<0.0001$ in pairwise permutation tests) (Table 3), except between $D$. lichenella-D. triquetrella and $D$. triquetrella-S. listerella. The Procrustes distances ranged from 0.0667 (D. fennicella vs. D. lazuri) to 0.4351 (D. lazuri vs. S. listerella). 


\section{DISCUSSION}

Overall, we address the problem of the inaccuracy of traditional morphological methods for identifying species of Dahliciini. Because of problems associated with their unresolved taxonomic status, we suggest alternative approaches for delimiting species based on molecular methods and geometric morphometrics.

\section{Species delimitation by molecular methods}

Our classification of the different species of moths is supported by $\mathrm{NJ}$ trees and $\mathrm{K} 2 \mathrm{P}$ distances which are mainly used for barcoding (Hebert et al., 2004; Che et al., 2012; Pradeep Kumar et al., 2012). The observed variation in branch length within certain species specific clusters (i.e. D. lichenella 10-EVO-59-F) is due to intraspecific variation within the species.

We report seven groups of species: two parthenogenetic: D. fennicella, $D$ triquetrella, and five sexual species: D. lazuri, D. lichenella, S. rupicolella, D. charlottae, S. listerella. Siederia cembrella, which has a questionable taxonomic status (Sobczyk, 2011), was not present at the sites we sampled. Previous analyses (Grapputo et al., 2005 ) only report 4 sexual species, since $D$. lichenella is considered to be strictly parthenogenetic and rare.

Our results based on Bayesian Inference of the mitochondrial (COI) and nuclear (MDH) gene fragments are congruent in terms of the species specific clusters identified in NJ trees. Overall, there was no strong support for the monophyly of Dahlica and Siederia. Furthermore, the tree topologies were broadly similar and provided evidence that the group comprising the parthenogenetic $D$. fennicella and sexual $D$. lazuri and D. lichenella is monophyletic. In contrast, the phylogenetic relationships of the rest of the species were variable. The paraphyletic status of D. fennicella and D. lazuri, based on the MDH gene fragment, might reflect incomplete lineage sorting or multiple transitions to parthenogenesis in D. fennicella (Chevasco et al., 2013). Unfortunately, we could not characterize the morphology of Estonian D. fennicella using geometric morphometrics because only dead larvae were present in the samples.

Based on the analysis of the MDH gene fragment we ruled out the possibility of hybridization from our set of samples and suggest that hybridization between the sexual species might not occur in the wild. However, some sexual species (D. lazuri, D. lichenella and S. rupicolella) do hybridize under laboratory conditions (J.A Elzinga, pers. obs.). In addition, the origin of parthenogenesis does not appear to be by hybridization (Chevasco et al., 2013).

Both mitochondrial fragments proved to be useful for distinguishing between species, even the short COII fragment. According to Roe \& Sperling (2007) the reliability of short fragments is questionable. Smaller DNA regions may misrepresent intra and inter-specific distances, provide insufficient nucleotide variation and might contain regions of unusual nucleotide divergence. In contrast, longer fragments, such as that of COI, minimize these risks. Despite all the possible disadvantages of a short fragment, the analysis of COII resulted in the same species specific clusters as that of COI. Moreover, the amplification of COII in degraded tissues was particularly useful for identifying parasitized bagworm moths (Elzinga et al., 2011a, 2012).

In spite of the apparent simplicity of DNA barcoding, the idea of species specific clusters is sometimes suggested to be insufficient for identifying a specimen. One reason is that there is always the possibility of unidentifiable or wrongly placed non-identical sequences (Will \& Rubinoff, 2004). Moreover, ambiguous data might be difficult to detect because the NJ algorithms generate a single tree (Meier et al., 2006). Based on these potential problems, we complemented our analysis by using other identification criteria, such as "Best Close Match" and "All Species Barcodes" (Meier et al., 2006). Our results demonstrate the standardized barcode (COI) performed best, was not ambiguous and only a low percentage $(1.04 \%)$ of its assignments were incorrect. In contrast, the use of the COII fragment resulted in ambiguous identifications and a higher percentage of incorrect assignments.

Distance threshold values of $2 \%$ or $3 \%$ were commonly used in earlier barcoding studies (Ross et al., 2008). In contrast, a more recent study (Ratnasingham \& Hebert, 2007) used a threshold value of $1 \%$. Threshold values help to establish boundaries for species delimitation since the DNA barcoding approach is based on genetic divergence. However, our data indicates these particular values may not be appropriate for the Narycinae. Using the 3\% divergence criterion (Hebert et al., 2003) the COII fragment produced only one species specific cluster for $S$. listerella. The alternative distance threshold value suggested by Ratnasingham \& Herbert (2007) of 1\% resulted in the generation of five species clusters ( $S$. listerella, D. lazuri, $D$. triquetrella, D. fennicella and $D$. lichenella). In spite of the better performance of the COI in terms of "Best Close Match" and "All Species Barcodes" the distance threshold values of $3 \%$ and $1 \%$ for the COI fragment only distinguished species specific clusters for D. charlottae, D. triquetrella and S. rupicolella.

The BIN algorithm was much more accurate in delimiting the seven species that we analyzed. Only D. fennicella (parthenogenetic) and D. lazuri (sexual) shared the same cluster. This may be because of the sister species status observed in the COI tree or that $D$. fennicella originated by autoploidization of $D$. lazuri (Chevasco et al., 2013).

A third method of estimating the distance threshold, the barcoding gap, is proposed by Meyer \& Paulay (2005). The barcoding gap is the difference between intra-specific and mean inter-specific, congeneric distances. However, its use is also controversial, as Meier et al. (2008) suggest that the mean inter-specific distance is inaccurate and that only the smallest inter-specific distances should be used. Thus, the threshold issue continues to be debated (Hickerson et al., 2006; Rubinoff, 2006; Ward et al., 2009) due to its lack of universality. We also suggest that the application of threshold limits might be artificial and not applicable to every species, which is supported by studies on 
other systems. In drosophilids none of the distance threshold criteria were suitable for delimiting species (Yassin et al., 2010). The same situation is reported for two species of parasitoids (Trachyarus solyanikovi and $T$. fuscipes) (Elzinga et al., 2011a). Strutzenberger et al. (2011) even suggest a species specific threshold value of $2 \%$ for Eois moths. The lack of universality in divergence thresholds and species level divergence cut-off values has raised questions about whether genetic distance should be included as a component of barcoding in taxonomy (Meyer \& Paulay, 2005; Vogler, 2006; Wiemers \& Fiedler, 2007). Clearly, further work is needed to determine the usefulness of threshold limits in species delimitation.

DNA barcoding is dependent on correctly identified voucher specimens, which can be used in conjunction with newly generated sequences, if one is to define the species specific groups (Valentini et al., 2009). Ideally, reference sequences should be obtained from type specimens (Meyer \& Paulay, 2005). Unfortunately, some type specimens of Dahliciini have been lost (Sobczyk, 2011). Additionally, DNA barcoding retains the problems of accurately naming species and identifying sequences that do not match reference sequences.

Species names used in our study follow those reported in Grapputo et al. (2005) and are based on mtDNA and traditional morphology. The species identification was based on where they were collected, larval case and shape of wing scales of males, but no quantitative analysis was performed. The morphological identification matched the mtDNA haplotypes of $D$. fennicella and D. triquetrella. However, Grapputo et al. (2005) report some mismatches between morphological and DNA-based approaches. For instance, the COII references SR2, SR2a, SR4 and SR2b (Fig. S1) (SR stands for S. rupicolella based on morphology) clustered with $S$ listerella sequences. Grapputo et al. (2005) relied on the morphological identification of the Finnish specimens. Therefore, SR2, SR2a, SR4 and SR2b are referred to as $S$. listerella (Fig. S1). Moreover, DL3, DL4 and DL4a (DL stands for D. lazuri based on morphology) clustered with $D$. charlottae sequences. Grapputo et al. (2005) considers the morphological identification of D. lazuri to be unreliable, thus DL3, DL4 and DL4a are denominated as D. charlottae (Fig. S1). Nevertheless, we cannot rule out the uncertainty of species naming among $S$. listerella, S. rupicolella, D. lazuri and $D$. charlottae. Another issue is that D. lichenella is only considered to be parthenogenetic in Finland (Suomalainen, 1980; Sobczyk, 2011). Nonetheless, the occurrence of a sexual form denominated $D$. lichenella fumosella (Heinemann, 1870) is reported (Suomalainen, 1980). According to our preliminary classification based on the COII, the sexuals that we identified as D. lichenella clustered together with Austrian D. lichenella fumosella (not shown), which is considered to be a sexual form of the parthenogenetic D. lichenella (Pro Natura, 1997). Throughout our sampling, strictly parthenogenetic $D$. lichenella were not found. An explanation for the absence of this particular species could be that we did not include sites close to Rauma (Finland), where Grapputo et al. (2005) found parthenogenetic $D$. lichenella.

We conducted a species specific search in the BOLD database in an attempt to gain more insights into the unresolved taxonomy of these species. Based on the standardized DNA barcode (COI), our sequences from $S$. listerella, D. charlottae, D. lazuri, D. fennicella and D. lichenella did not generate a species specific match with any BOLD barcodes. Only D. lichenella, D. fennicella and $S$. listerella matched the vouchers for the same species with the possibility of a potential match. Our findings might reflect the lack of consistency in the naming of species due to the great difficulty in identifying them using traditional morphological methods. Therefore, we employed geometric morphometrics to determine its potential applicability for species discrimination in bagworm moths.

\section{Morphological analysis of males}

Wing scale analysis yielded poor species delimitation, since there were no significant differences, based on geometric morphometrics, between the following pairs of species: D. charlottae-D. lazuri, D. charlottae-S. rupicolella and D. lazuri-S. rupicolella. Therefore, based on our samples we conclude that wing scales are unlikely to be a suitable morphological character for species differentiation. Variation in wing venation (Albrecht \& Kaila, 1997) and/or wing shape (Roggero \& d'Entrèves, 2005) might be useful for species delimitation in Lepidoptera. Unfortunately, we could not use wing shape or venation because the tips and bases of the wings of the moths in most of our samples were damaged.

As in other studies on Lepidoptera (Mutanen, 2005; Mutanen et al., 2007; Dapporto, 2008, 2010), we demonstrate that differences in male genitalia are an effective way of discriminating between species of the genera Dahlica and Siederia. In fact, the extensive use of geometric morphometrics to search for differences among taxa is strongly recommended by Mutanen \& Pretorius (2007). The use of geometric morphometrics is an alternative to the genital index (Suomalainen, 1980) and traditional morphometrics for identifying bagworm moths. Traditional morphometric methods applied to male genitalia in our study species were not able to differentiate the two species of the genus Siederia (V. Chevasco, unpubl.) In spite of the effectiveness of male genitalia and molecular methods, the species delimitation of living specimens remains unresolved.

Interestingly, the smallest range of Mahalanobis distances in wing scales and genitalia was between $D$. lazuri and $D$. lichenella. The similarity between these two species was corroborated by their monophyletic relationship indicated in the mitochondrial and nuclear gene trees.

\section{Morphological analysis of females}

The capito-prosternal plate of the female pupa was not entirely suitable for species delimitation purposes. In spite of this, we demonstrate the better performance of geometric morphometrics when compared to traditional methods. Only D. triquetrella is discriminated on the 
basis of the capito-prosternal plate when assessed using traditional morphometrics (V. Chevasco, unpubl.). Our findings revealed no significant differences between $D$. lichenella-D. triquetrella and D. triquetrella-S. listerella. Nevertheless, the lack of significant differences in the capito-prosternal plates of these species is easily resolved because $D$. triquetrella is parthenogenic and the shape of larval case is different (Suomalainen, 1980).

The geometric morphometric analysis of the capitoprosternal plate yielded a small range of Mahalanobis distances between $D$. fennicella and D. lichenella. These findings helped us confirm the monophyly of these two species, as indicated by the mitochondrial and nuclear gene trees.

In summary, our results show that only male genitalia have an equivalent discriminatory power to DNA barcoding. Other characteristics, such as wing scales and the capito-prosternal plate of female pupae have a poorer discriminatory power than molecular methods.

\section{CONCLUSION}

Regardless of the unresolved issues concerning the uncertainty in the naming of the species, the taxonomic units described herein remain valid. We suggest that comparison of multiple sources of data, such as tree based identification techniques together with male genitalia, is effective for some species of Dahliciini. Nonetheless, barcoding has its limitations, such as the unresolved taxonomic status of species, dependency on the availability of reference sequences and lack of a consensus regarding the application of distance thresholds. Despite these limitations, DNA barcoding should continue to be used for a variety of taxonomic, biodiversity and ecological applications.

ACKNOWLEDGEMENTS. S. Viinikainen and K. Suisto provided laboratory assistance at the University of Jyväskylä. We are grateful to two anonymous reviewers for constructive comments on the MS. We also thank R. Hegna for reviewing the language. This work was funded by the Academy of Finland project no. 116892 to $\mathrm{AG}$.

\section{REFERENCES}

Albrecht A. \& Kaila L. 1997: Variation of wing venation in Elachistidae (Lepidoptera: Gelechioidea): methodology and implications to systematics. - Syst. Entomol. 22: 185-198.

BARRETT R.D.H. \& HeBert P.D.N. 2005: Identifying spiders through DNA barcodes. - Can. J. Zool. 83: 481-491.

Bengtsson B.A., Palmqvist G. \& Johansson R. 2008: Nationalnyckeln till Sveriges flora och fauna (Encyclopedia of the Swedish Flora and Fauna), DE 1-13. Fjärilar: Käkmalar säckspinnare. Lepidoptera: Micropterigidae - Psychidae. Artdatabanken, Sveriges lantbruksuniversitet, Uppsala, $646 \mathrm{pp}$.

BIRKY C. 1999: An even broader perspective on sex and recombination. - J. Evol. Biol. 12: 1013-1016.

CARDINI A. 2003: The geometry of the marmot (Rodentia: Sciuridae) mandible: phylogeny and patterns of morphological evolution. - Syst. Biol. 52: 186-205.

Che J., Chen H.M., Yang J.X., Jin J.Q., Jiang K., Yuan Z.Y., Murphy R.W. \& Zhang Y.P. 2012: Universal COI primers for
DNA barcoding amphibians. - Mol. Ecol. Resour. 12: 247-258.

Chevasco V., Elzinga J.A., Virnikainen S.M., Mappes J. \& GALARZA J.A. 2012: Unexpected genetic variability in the parthenogenetic bag worm moth Dahlica fennicella (Lepidoptera: Psychidae) revealed by novel microsatellite markers. - Conserv. Genet. Resour. 4: 159-162.

Chevasco V., Elzinga J.A., Galarza J., Mappes J. \& Grapputo A. 2013: Investigating the origin of parthenogenesis and ploidy level in Dahlica fennicella (Lepidoptera: Psychidae). - Ann. Zool. Fenn. 50: 125-145.

ClerCK K.A. 1759: [Titelkupfer:] Caroli Clerck ... Icones Insectorum rariorum Cum Nominibus eorum trivialibus, locisque e C. Linnaei Arch: R: et Equ: Aur: Syst: Nat: allegatis Holmiae 1759. [2. Titelblatt:] Icones Insectorum rariorum. Sectio Prima. Holmiae $4^{\circ}$ Sectio 1: Titelkupfer +2 . Titelbl. $+[4]+$ [4] p. col. Taf. [1][16].

DAPPORTO L. 2008: Geometric morphometrics reveal male genitalia differences in the Lasiommata megera/paramegaera complex (Lepidoptera, Nymphalidae) and the lack of a predicted hybridization area in the Tuscan Archipelago. $-J$. Zool. Syst. Evol. Res. 46: 224-230.

DAPPORTO L. 2010: Satyrinae butterflies from Sardinia and Corsica show a kaleidoscopic intraspecific biogeography (Lepidoptera, Nymphlidae). — Biol. J. Linn. Soc. 100: 195-212.

Darriba D., Taboada G.L., Doallo R. \& Posada D. 2012: jModelTest 2: more models, new heuristics and parallel computing. - Nat. Methods 9: 772-772.

Debat V., Béagin M., Legout H. \& David J.R. 2003: Allometric and nonallometric components of Drosophila wing shape respond differently to developmental temperature. - Evolution 57: 2773-2784.

DIERL W. 1966: Zur Kenntnis einiger Solenobia-Arten (Lepidoptera: Psychidae). Ein Beitrag zur Fauna Bavarica. - Mitt. Münch. Entomol. Ges. 56: 190-196.

Dryden I. \& Mardia K. 1998: Statistical Analysis of Shape. Wiley, Chichester, $376 \mathrm{pp}$.

Elzinga J.A., Zwakhals K., Mappes J. \& Grapputo A. 2011a: The parasitoid species complex associated with sexual and parthenogenetic Naryciinae (Lepidoptera: Psychidae): Integrating ecological and molecular analyses. - Eur. J. Entomol. 108: 635-650.

Elzinga J.A., Chevasco V., Grapputo A. \& Mappes J. 2011b: Influence of male mating history on female reproductive success among monandrous Naryciinae (Lepidoptera: Psychidae). - Ecol. Entomol. 36: 170-180.

Elzinga J., Chevasco V., Mappes J. \& Grapputo A. 2012: Low parasitism rates in parthenogenetic bagworm moths do not support the parasitoid hypothesis for sex. $-J$. Evol. Biol. 25: 2547-2558.

Foottit R., Maw H., Havill N., Ahern R. \& Montgomery M. 2009: DNA barcodes to identify species and explore diversity in the Adelgidae (Insecta: Hemiptera: Aphidoidea). - Mol. Ecol. Resour. 9: 188-195.

Gossner M. \& Hausmann A. 2009: DNA barcoding enables the identification of caterpillars feeding on native and alien oak. - Mitt. Münch. Entomol. Ges. 99: 135-140.

Grapputo A., Kumpulainen T. \& Mappes J. 2005: Phylogeny and evolution of parthenogenesis in Finnish bagworm moth species (Lepidoptera: Psychidae: Naryciinae) based on mtDNA-markers. - Ann. Zool. Fenn. 42: 141-160.

Hall B. 2011: Phylogenetic Trees Made Easy: A How-to Manual. Sinauer Associates, Sunderland, MA, 282 pp.

Hättenschwiler P. 1985: Psychidae. In Heath J. \& Emmet A.M. (eds): The Moths and Butterflies of Great Britain and Ireland. Harley Books, Colchester, pp. 128-151. 
HAUSER E. 2004: Vergleichende Morphologie ausgewählter Arten der Gattung Dahlica Enderlein 1912 (D. fumosella, D lichenella, D. fennicella, D. charlottae) mit einem Vermerk zu Solenobia norvegica (Lepidoptera, Psychidae). - Denisia 13: $305-316$.

Hebert P.D.N., Cywinska A. \& Ball S.L. 2003: Biological identifications through DNA barcodes. - Proc. R. Soc. Lond. (B, Biol. Sci.) 270: 313-321.

Hebert P.D.N., Stoeckle M.Y., Zemlak T.S. \& Francis C.M. 2004: Identification of birds through DNA barcodes. - PLoS Biol. 2: e312.

HeInEmann H. 1870: Die Schmetterlinge Deutschlands und der Schweiz systematisch bearbeitet. Nebst analytischen Tabellen zum Bestimmen der Schmetterlinge. Zweite Abtheilung. Kleinschmetterlinge. Die Motten und Federmotten. 2 (1). C.A. Schwentschke \& Sohn, Braunschweig, pp. 1-388.

Hickerson M.J., Meyer C.P. \& Moritz C. 2006: DNA barcoding will often fail to discover new animal species over broad parameter space. - Syst. Biol. 55: 729-739.

Hillis D.M. \& Bull J.J. 1993: An empirical test of bootstrapping as a method for assessing confidence in phylogenetic analysis. - Syst. Biol. 42: 182.

HÜBNER J. 1800-1838: [imprint "1805"]. Sammlung europäischer Schmetterlinge Horde 3. Bombyces-Spinner [continued by C. Geyer]. Augsburg, pp. 101-154, pls 1-83.

Jin Q., Han H., Hu X., Li X., Zhu C., Ho S.Y., Ward R.D. \& ZHANG A. 2013: Quantifying species diversity with a DNA barcoding-based method: Tibetan moth species (Noctuidae) on the Qinghai-Tibetan Plateau. _ PloS One 8: e64428.

KIMURA M. 1980: A simple method for estimating evolutionary rates of base substitutions through comparative studies of nucleotide sequences. - J. Mol. Evol. 16: 111-120.

KLINGENBERG C.P. 2011: MorphoJ: an integrated software package for geometric morphometrics. - Mol. Ecol. Resour. 11: $353-357$

Klingenberg C.P. \& Monteiro L.R. 2005: Distances and directions in multidimensional shape spaces: implications for morphometric applications. - Syst. Biol. 54: 678-688.

Klingenberg C.P., Barluenga M. \& Meyer A. 2003: Body shape variation in cichlid fishes of the Amphilophus citrinellus species complex. - Biol. J. Linn. Soc. 80: $397-408$

Klingenberg C., Duttke S., Whelan S. \& Kim M. 2012: Developmental plasticity, morphological variation and evolvability: a multilevel analysis of morphometric integration in the shape of compound leaves. - J. Evol. Biol 25: 115-129.

Kumpulainen T., Grapputo A. \& Mappes J. 2004: Parasites and sexual reproduction in psychid moths. - Evolution 58: $1511-1520$

Lanave C., Preparata G., Sacone C. \& Serio G. 1984: A new method for calculating evolutionary substitution rates. $-J$. Mol. Evol. 20: 86-93.

LinNaeus C. 1758: Caroli Linnaei ... Systema Naturae per regna tria naturae, secundum classes, ordines, genera, species, cum characteribus, differentiis, synonymis, locis. Editio decima, reformata. Laurentii Salvii, Holmiae, i-vi: pp. 1-824.

Linnaeus C. 1761: Fauna Suecica sistens animalia Sueciae regni: Mammalia, Aves, Amphibia, Pisces, Insecta, Vermes. Distributa per classes ordines, genera species, cum differentiis specierum, synonymis auctorum, nominibus incolarum locis natalium, descriptionibus insectorum. Laurentii Salvii, Stockholmiae [xlviii] 2 pls +46 : pp. 1-579.

Meier H. 1957: Ein neues Subgenus und neue Arten aus der Gattung Solenobia Dup. (Lep. Psych.). — Nachr. Bayer. Entomol. 6: 55-61.
Meier R., Shiyang K., Vaidya G. \& NG P.K.L. 2006: DNA barcoding and taxonomy in Diptera: A tale of high intraspecific variability and low identification success. - Syst. Biol. 55: $715-728$.

Meier R., Zhang G. \& Ali F. 2008: The use of mean instead of smallest interspecific distances exaggerates the size of the "barcoding gap" and leads to misidentification. Syst. Biol. 57: 809-813.

Meyer C.P. \& Paulay G. 2005: DNA barcoding: error rates based on comprehensive sampling. - PLoS Biol. 3: e422.

MulLeR H. 1964: The relation of recombination to mutational advance. - Mutat. Res/Fund. Mol. 1: 2-9.

Mutanen M. 2005: Delimitation difficulties in species splits: a morphometric case study on the Euxoa tritici complex (Lepidoptera, Noctuidae). - Syst. Entomol. 30: 632-643.

Mutanen M. \& Pretorius E. 2007: Subjective visual evaluation vs. traditional and geometric morphometrics in species delimitation: a comparison of moth genitalia. - Syst. Entomol. 32: 371-386.

Mutanen M., Itamies J. \& Kaila L. 2007: Heliozela resplendella (Stainton, 1851) and H. hammoniella Sorhagen, 1885: two valid species distinguishable in the genitalia of both sexes and life histories (Heliozelidae). — Nota Lepidopt. 30: 79.

Mutanen M., Wahlberg N. \& Kaila L. 2010: Comprehensive gene and taxon coverage elucidates radiation patterns in moths and butterflies. - Proc. R. Soc. Lond. (B, Biol. Sci.) 277: 2839-2848

PalmQvist G. 2008: Psychidae, Säckspinnare (Psychidae, Bagworm Moths). In Bengtsson B.A. \& Palmqvist G. (eds): Nationalnyckeln till Sveriges Flora och Fauna. Fjärilar: Käkmalar Säckspinnare. Lepidoptera: Micropterigidae Psychidae. [Encyclopedia of the Swedish Flora and Fauna. Lepidoptera: Micropterigidae - Psychidae.] Swedish Species Information Centre, Swedish University of Agricultural Sciences, Uppsala, pp. 492-557.

Park D., Foottit R., Maw E. \& Hebert P.D. 2011: Barcoding bugs: DNA-based identification of the true bugs (Insecta: Hemiptera: Heteroptera). — PloS One 6: e18749.

Pérez-Losada M., Bloch R., Breinholt J.W., Pfenninger M. \& Domínguez J. 2012: Taxonomic assessment of Lumbricidae (Oligochaeta) earthworm genera using DNA barcodes. Eur. J. Soil Biol. 48: 41-47.

Posada D. \& Crandall K.A. 1998: Modeltest: testing the model of DNA substitution. - Bioinformatics 14: 817-818.

Pradeep Kumar N., Srinivasan R. \& Jambulingam P. 2012: DNA barcoding for identification of sand flies (Diptera: Psychodidae) in India. - Mol. Ecol. Resour. 12: 414-420.

Pro Natura - Lepidopterologen-Arbeitsgruppe (eds) 1997: Psychidae Sackträger Schmetterlinge und ihre Lebensräume. Arten, Gefärdung, Schutz. Schweiz und Angrenzende gebieten. Band 2. Schweizerische Bund fur Naturschutz, Basel, pp. 165-308.

Ratnasingham S. \& Hebert P.D.N. 2007: BOLD: The Barcode of Life Data System (http://www. barcodinglife. org). - Mol. Ecol. Notes 7: 355-364.

Ratnasingham S. \& Hebert P.D. 2013: A DNA-based registry for all animal species: The Barcode Index Number (BIN) System. - PloS One 8: e66213.

Rhainds M., Davis D.R. \& Price P.W. 2009: Bionomics of bagworms (Lepidoptera: Psychidae). - Annu. Rev. Entomol. 54: 209-226.

Rice W.R. \& Friberg U. 2009: A graphical approach to lineage selection between clonals and sexuals. In Schön I., Martens K. \& van Dijk P. (eds): Lost Sex. The Evolutionary Biology of Parthenogenesis. 1st ed. Springer Science + Business Media, Dordrecht, pp. 75-97. 
Roe A.D. \& Sperling F.A.H. 2007: Patterns of evolution of mitochondrial cytochrome c oxidase I and II DNA and implications for DNA barcoding. - Mol. Phylogenet. Evol. 44: 325-345.

Roggero A. \& D'Entrèves P.P. 2005: Geometric morphometric analysis of wings variation between two populations of the Scythris obscurella species-group: geographic or interspecific differences? (Lepidoptera: Scythrididae). - SHILAP / Rev. Lepidopt. 33: 101-112.

RohlF F. 2010: tpsDig, version 2.16. Department of Ecology and Evolution, State University of New York, Stony Brook.

RohlF F. 2012: TpsUtil, file utility program. version 1.53. Department of Ecology and Evolution, State University of New York at Stony Brook, 2010v (program).

Ronquist F., Teslenko M., van der Mark P., Ayres D.L., Darling A., Höhna S., Larget B., Liu L., Suchard M.A. \& HuelSENBECK J.P. 2012: MrBayes 3.2: efficient Bayesian phylogenetic inference and model choice across a large model space. - Syst. Biol. 61: 539-542.

Ross H.A., Murugan S. \& Li W.L.S. 2008: Testing the reliability of genetic methods of species identification via simulation. - Syst. Biol. 57: 216-230.

RuBINOFF D. 2006: Utility of mitochondrial DNA barcodes in species conservation. - Conserv. Biol. 20: 1026-1033.

Rubinoff D. \& Holland B.S. 2005: Between two extremes: mitochondrial DNA is neither the panacea nor the nemesis of phylogenetic and taxonomic inference. - Syst. Biol. 54: 952-961.

Ruiz-Lopez F., Wilkerson R.C., Conn J.E., McKeon S.N., Levin D.M., Quiñones M.L., PóvoA M.M. \& Linton Y. 2012: DNA barcoding reveals both known and novel taxa in the Albitarsis group (Anopheles: Nyssorhynchus) of Neotropical malaria vectors. - Paras. Vect. 5: 1-12.

SAUTER W. 1954: Zur Morphologie und Systematik der schweizerischen Solenobia-Arten (Lep. Psychidae). - Mitt. Schweiz. Entomol. Ges. 27: 429-434.

SAUTER W. 1956: Morphologie und Systematik schweizerischen Solenobia-arten. - Rev. Suisse Zool. 63: 451-550.

Simon C., Frati F., Beckenbach A., Crespi B., Liu H. \& Flook P. 1994: Evolution, weighting, and phylogenetic utility of mitochondrial gene sequences and a compilation of conserved polymerase chain reaction primers. - Ann. Entomol. Soc. Am. 87: 651-701.

Smith M.A., Fernández-Triana J., Eveleigh E., Gómez J., Guclu C., Hallwachs W., Hebert P.D., Hrcek J., Huber J. \& JANZEN D. 2012: DNA barcoding and the taxonomy of Microgastrinae wasps (Hymenoptera, Braconidae): impacts after 8 years and nearly 20000 sequences. - Mol. Ecol. Resour. 13: $168-176$.

Soвсzyк T. 2011: Psychidae (Lepidoptera). World Catalogue of Insects. Vol. 10. Apollo Books, Stenstrup, 467 pp.

SRIVAthsan A. \& MeIer R. 2012: On the inappropriate use of Kimura-2-parameter (K2P) divergences in the DNAbarcoding literature. - Cladistics 28: 190-194.

Strutzennerger P., Brehm G. \& Fiedler K. 2011: DNA barcoding-based species delimitation increases species count of Eois (Geometridae) moths in a well-studied tropical mountain forest by up to 50\%. - Insect Sci. 18: 349-362.

Suomalainen E. 1970: Über die Solenobia-Arten Finnlands (Lepidoptera: Psychidae). — Ann. Zool. Fenn. 36: 139-142.

SuOMalainen E. 1980: The Solenobiinae species of Finland (Lepidoptera: Psychidae), with a description of a new species. - Insect Syst. Evol. 11: 458-466.

Tamura K., Peterson D., Peterson N., Stecher G., Nei M. \& KUMAR S. 2011: MEGA5: molecular evolutionary genetics analysis using maximum likelihood, evolutionary distance, and maximum parsimony methods. - Mol. Biol. Evol. 28: 2731-2739.

TAYlOR H. \& HARRIS W. 2012: An emergent science on the brink of irrelevance: a review of the past 8 years of DNA barcoding. - Mol. Ecol. Resour. 12: 377-388.

Valentini A., Pompanon F. \& Taberlet P. 2009: DNA barcoding for ecologists. — Trends Ecol. Evol. 24: 110-117.

VOGLER A.P. 2006: Will DNA barcoding advance efforts to conserve biodiversity more efficiently than traditional taxonomic methods? - Front. Ecol. Environ. 5: 270-272.

Wahlberg N. \& Wheat C.W. 2008: Genomic outposts serve the phylogenomic pioneers: designing novel nuclear markers for genomic DNA extractions of Lepidoptera. - Syst. Biol. 57: 231-242.

Ward R., Hanner R. \& Hebert P. 2009: The campaign to DNA barcode all fishes, FISH-BOL. - J. Fish Biol. 74: 329-356.

WIEMERS M. \& FIEDLER K. 2007: Does the DNA barcoding gap exist? A case study in blue butterflies (Lepidoptera: Lycaenidae). - Front. Zool. 4: 16.

WiLl K.W. \& RubinofF D. 2004: Myth of the molecule: DNA barcodes for species cannot replace morphology for identification and classification. - Cladistics 20: 47-55.

WILSON J.J. 2012: DNA barcodes for insects. In Kress J.W. \& Erikson D.L. (eds): DNA Barcodes: Methods and Protocols. Vol. 858. Humana Press, New York, pp. 17-46.

Yang Q., Kučerová Z., Li Z., Kalinović I., Stejskal V., Opit G. \& CAO Y. 2012: Diagnosis of Liposcelis entomophila (Insecta: Psocodea: Liposcelididae) based on morphological characteristics and DNA barcodes. - J. Stored Prod. Res. 48: 120-125.

Yassin A., Markow T.A., Narechania A., O’Grady P.M. \& DeSalle R. 2010: The genus Drosophila as a model for testing tree-and character-based methods of species identification using DNA barcoding. - Mol. Phylogenet. Evol. 57: 509-517.

ZHARKIKH A. 1994: Estimation of evolutionary distances between nucleotide sequences. - J. Mol. Evol. 39: 315-329.

Received May 30, 2013; revised and accepted July 26, 2013

\section{SUPPLEMENTARY INFORMATION}

\section{DNA analyses-Neighbor Joining trees}

We compared the results of a Neighbor Joining (NJ) approach based on partial sequences of both subunits (COI and COII) of the mitochondrial cytochrome oxidase gene. The outgroup sequence for both trees included a sequence for Narycia duplicella. The reliability of the trees was evaluated using a bootstrap test with 500 replicates.

\section{NJ tree for COII}

The inter-specific distances grouped the species of the genus Dahlica in a weakly supported single cluster (bootstrap: $32 \%$ ). Within the genus Dahlica, D. fennicella, D. lazuri and D. lichenella formed a well supported group (bootstrap: 97\%). Within this cluster, D. lazuri and D. fennicella had the lowest interspecific pairwise distance (1.5\%). The weakly supported $D$. triquetrella group (bootstrap: 38\%) showed the lowest divergence relative to $D$. charlottae $(3.1 \%)$, while the highest level of divergence in the genus Dahlica was observed between D. charlottae and D. lichenella (5.6\%). Members of the genus Siederia (S. listerella and S. rupicolella) did not form a single group. The cluster of S. listerella was better supported (bootstrap: 99\%) than that of S. rupicolella (bootstrap: 69\%). When comparing the genus Siederia with Dahlica the highest level of divergence was observed between $S$. listerella and D. lichenella (6.4\%). 


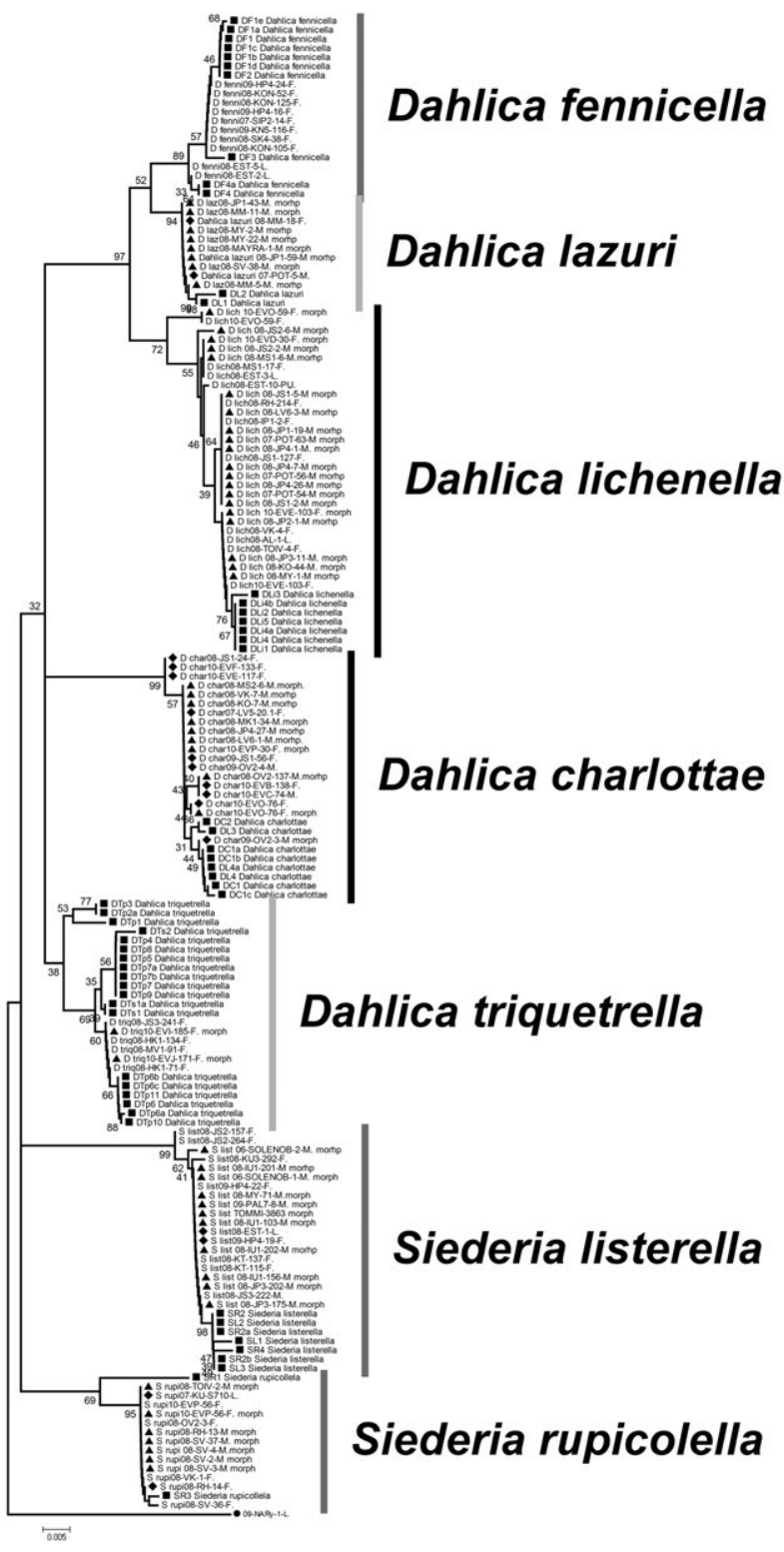

Fig. S1. Neighbor Joining tree based on K2P, pairwise deletion and bootstrap test of 500 replications for the COII (331 bp) of seven species of bagworm moths. Bootstrap values are indicated next to each node. The phylogenetic tree includes a reference sequence of Narycia duplicella as an outgroup (black circle). Each sample name indicates the species of moth: (Dlich $=D$. lichenella, Dlaz $=D$. lazuri, Dfenni $=D$. fennicella , Dtriq $=D$. triquetrella, Dchar $=D$. charlottae, Slist $=S$. listerella, Srupi $=S$. rupicolella), year of collection, sampling site, individual number and gender ( $\mathrm{M}$ or $\mathrm{F})$. The specimens that were included in the morphological analysis include the morph abbreviation (black triangle). The reference sequences (Grapputo et al., 2005) are indicated by a black square. Samples that were ambiguously / incorrectly identified by Taxon/DNA Species Identifier are indicated by a black diamond. The scale bar indicates the $\%$ of divergence.

Comparatively, S. rupicolella and D. charlottae had the lowest pairwise distance $(4.6 \%)$.

\section{NJ tree for COI}

The species of Dahlica and Siederia did not form the same independent groups as in the COII tree. As in the COII analysis,

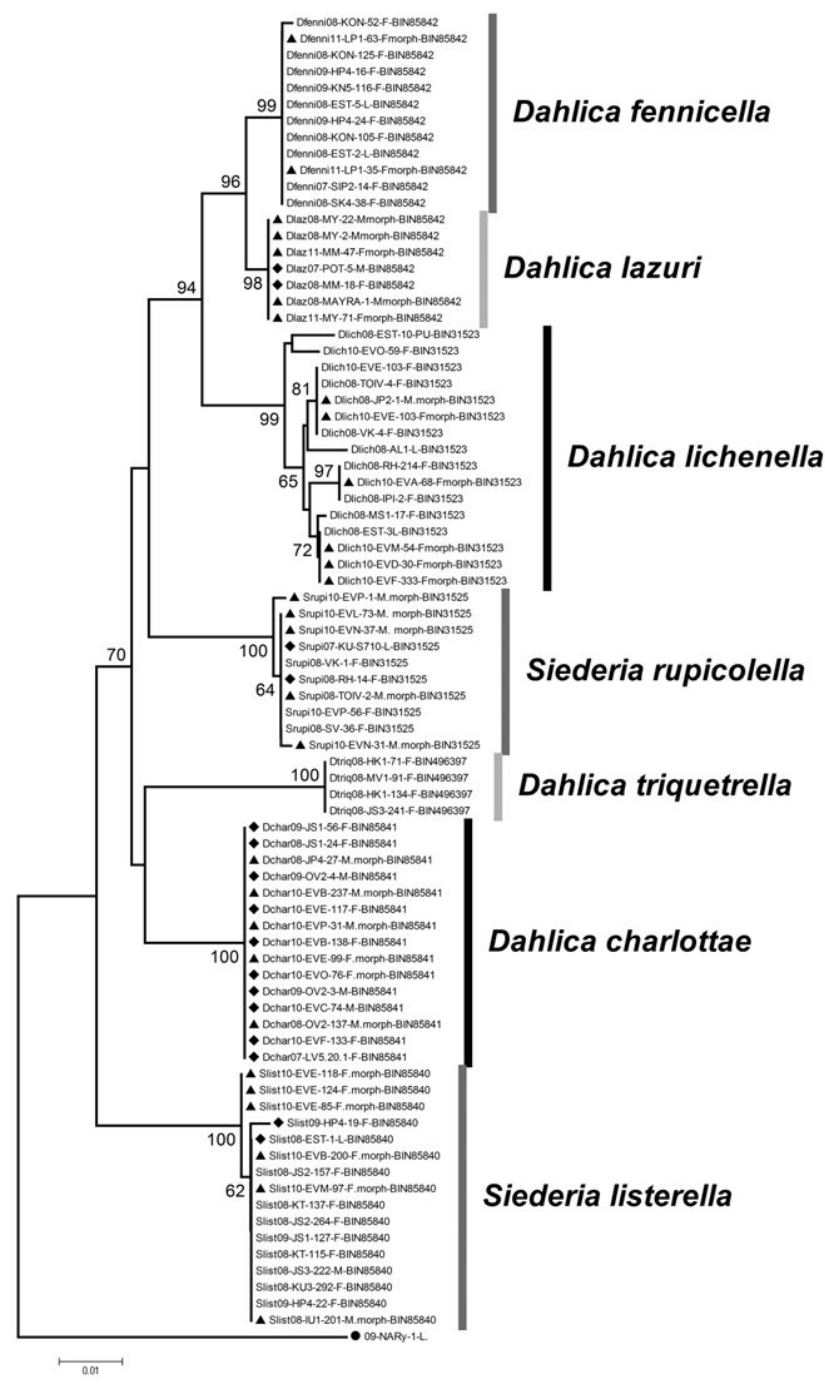

Fig. S2. Neighbor Joining tree based on K2P, pairwise deletion and bootstrap test of 500 replications for the COI $(657 \mathrm{bp})$ of seven species of bagworm moths. Bootstrap values are indicated next to each node. This phylogenetic tree includes a reference sequence of Narycia duplicella as an outgroup. Each sample name indicates the species of moth: $($ Dlich $=D$. lichenella, Dlaz $=D$. lazuri, Dfenni $=D$. fennicella, Dtriq $=D$. triquetrella, Dchar $=D$. charlottae, Slist $=$ S. listerella, Srupi $=S$. rupicolella), year of collection, sampling site, individual number, gender (M or F) and BIN (cluster ID). The specimens that were included in the morphological analysis include the morph abbreviation (black triangle). Samples that were ambiguously / incorrectly identified by Taxon/DNA Species Identifier are indicated by a black diamond. The scale bar indicates the $\%$ of divergence.

D. fennicella and D. lazuri exhibited the lowest pairwise distance $(0.9 \%)$. D. lichenella was in a well supported group (bootstrap: $99 \%$ ) with a degree of divergence of $3.1 \%$ in relation to D. lazuri and D. fennicella. Dahlica triquetrella and D. charlottae were sister species with a sequence divergence of $4.4 \%$. The highest degree of divergence within the genus Dahlica was between $D$. triquetrella and $D$. lichenella (5.7\%). The highest pairwise distance among all the species was between $D$. lichenella and S. listerella $(6.3 \%)$ 
TABLE S1. Summary of the locations and co-ordinates of the samples of the different species of bagworm moths used in this study. The type of tissue is indicated by L (larva) F (female), M (male), other (pupal remains) for a total of 196 individuals.

\begin{tabular}{|c|c|c|c|c|c|c|c|}
\hline Sampling sites & Coordinates & Genus & Species & $\mathrm{L}$ & $\mathrm{F}$ & $\mathrm{M}$ & Other \\
\hline AL (Åland) & $60^{\circ} 7^{\prime} \mathrm{N}, 19^{\circ} 54^{\prime} \mathrm{E}$ & Dahlica & lichenella & 1 & & & \\
\hline \multirow[t]{3}{*}{ EST (Tartu Estonia) } & $58^{\circ} 24^{\prime} \mathrm{N}, 26^{\circ} 52^{\prime} \mathrm{E}$ & Dahlica & fennicella & 2 & & & \\
\hline & & Dahlica & lichenella & 1 & & & 1 \\
\hline & & Siederia & listerella & 1 & & & \\
\hline \multirow[t]{2}{*}{ EVA } & $61^{\circ} 15.54^{\prime} \mathrm{N}, 25^{\circ} 15.35^{\prime} \mathrm{E}$ & Dahlica & charlottae & & 1 & & \\
\hline & & Dahlica & lichenella & & 1 & & \\
\hline \multirow[t]{2}{*}{ EVB } & $61^{\circ} 15.19^{\prime} \mathrm{N}, 25^{\circ} 14.27^{\prime} \mathrm{E}$ & Dahlica & charlottae & & 4 & 1 & \\
\hline & & Siederia & listerella & & 1 & & \\
\hline \multirow[t]{2}{*}{ EVC } & $61^{\circ} 13.57^{\prime} \mathrm{N}, 25^{\circ} 11.03^{\prime} \mathrm{E}$ & Dahlica & charlottae & & 1 & 1 & \\
\hline & & Dahlica & lichenella & & 1 & & \\
\hline \multirow[t]{2}{*}{ EVD } & $61^{\circ} 12.38^{\prime} \mathrm{N}, 25^{\circ} 8.95^{\prime} \mathrm{E}$ & Dahlica & lichenella & & 1 & & \\
\hline & & Siederia & rupicolella & & 1 & & \\
\hline \multirow[t]{4}{*}{ EVE } & $61^{\circ} 12.53^{\prime} \mathrm{N}, 25^{\circ} 9.09^{\prime} \mathrm{E}$ & Dahlica & charlottae & & 3 & & \\
\hline & & Dahlica & lichenella & & 2 & & \\
\hline & & Siederia & listerella & & 3 & & \\
\hline & & Siederia & rupicolella & & 1 & & \\
\hline \multirow[t]{2}{*}{ EVF } & $61^{\circ} 12.75^{\prime} \mathrm{N}, 25^{\circ} 9.29^{\prime} \mathrm{E}$ & Dahlica & charlottae & & 1 & & \\
\hline & & Dahlica & lichenella & & 1 & & \\
\hline \multirow[t]{2}{*}{ EVG } & $61^{\circ} 13.28^{\prime} \mathrm{N}, 25^{\circ} 9.24^{\prime} \mathrm{E}$ & Dahlica & charlottae & & 1 & & \\
\hline & & Siederia & rupicolella & & 2 & & \\
\hline \multirow[t]{2}{*}{ EVH } & $61^{\circ} 13.18^{\prime} \mathrm{N}, 25^{\circ} 9.48^{\prime} \mathrm{E}$ & Dahlica & charlottae & & 1 & & \\
\hline & & Dahlica & lichenella & & 1 & & \\
\hline \multirow[t]{3}{*}{ EVI } & $61^{\circ} 13.78^{\prime} \mathrm{N}, 25^{\circ} 3.61^{\prime} \mathrm{E}$ & Dahlica & charlottae & & 1 & & \\
\hline & & Dahlica & lichenella & & 2 & & \\
\hline & & Dahlica & triquetrella & & 1 & & \\
\hline \multirow[t]{3}{*}{ EVJ } & $61^{\circ} 12.72^{\prime} \mathrm{N}, 25^{\circ} 1.51^{\prime} \mathrm{E}$ & Dahlica & charlottae & & 1 & & \\
\hline & & Siederia & rupicolella & & 1 & & \\
\hline & & Dahlica & triquetrella & & 4 & & \\
\hline \multirow[t]{2}{*}{ EVL } & $61^{\circ} 12.19^{\prime} \mathrm{N}, 25^{\circ} 4.15^{\prime} \mathrm{E}$ & Dahlica & lichenella & & 1 & & \\
\hline & & Siederia & rupicolella & & & 1 & \\
\hline \multirow[t]{2}{*}{ EVM } & $61^{\circ} 16.19^{\prime} \mathrm{N}, 25^{\circ} 9.45^{\prime} \mathrm{E}$ & Dahlica & lichenella & & 2 & & \\
\hline & & Siederia & listerella & & 1 & & \\
\hline \multirow[t]{2}{*}{ EVN } & $61^{\circ} 16.14^{\prime} \mathrm{N}, 25^{\circ} 8.45^{\prime} \mathrm{E}$ & Siederia & rupicolella & & 1 & 2 & \\
\hline & & Siederia & listerella & & 2 & & \\
\hline \multirow[t]{4}{*}{ EVO } & $61^{\circ} 16.71^{\prime} \mathrm{N}, 25^{\circ} 8.52^{\prime} \mathrm{E}$ & Dahlica & charlottae & & 2 & & \\
\hline & & Dahlica & lichenella & & 2 & & \\
\hline & & Siederia & listerella & & 2 & & \\
\hline & & Siederia & rupicolella & & 1 & & \\
\hline \multirow[t]{2}{*}{ EVP } & $61^{\circ} 17.08^{\prime} \mathrm{N}, 25^{\circ} 10.19^{\prime} \mathrm{E}$ & Dahlica & charlottae & & 1 & 1 & \\
\hline & & Siederia & rupicolella & & 3 & 3 & \\
\hline EVQ & $61^{\circ} 25.23^{\prime} \mathrm{N}, 25^{\circ} 1.16^{\prime} \mathrm{E}$ & Siederia & rupicolella & & 1 & 1 & \\
\hline EVR & $61^{\circ} 25.02^{\prime} \mathrm{N}, 25^{\circ} 0.24^{\prime} \mathrm{E}$ & Siederia & rupicolella & & 1 & & \\
\hline HK (Hiekkapohja) & $62^{\circ} 21.02^{\prime} \mathrm{N}, 25^{\circ} 46.44^{\prime} \mathrm{E}$ & Dahlica & triquetrella & & 2 & & \\
\hline \multirow[t]{2}{*}{ HP (Haapaniemi) } & $62^{\circ} 13.43^{\prime} \mathrm{N}, 25^{\circ} 50.57^{\prime} \mathrm{E}$ & Dahlica & fennicella & & 3 & & \\
\hline & & Siederia & listerella & & 2 & & \\
\hline IP & $62^{\circ} 8.2^{\prime} \mathrm{N}, 25^{\circ} 52.0^{\prime} \mathrm{E}$ & Dahlica & lichenella & & 1 & & \\
\hline \multirow[t]{2}{*}{ IU } & $62^{\circ} 10.58^{\prime} \mathrm{N}, 25^{\circ} 45.2^{\prime} \mathrm{E}$ & Dahlica & charlottae & & & 1 & \\
\hline & & Siederia & listerella & & & 4 & \\
\hline JL & $62^{\circ} 13.38^{\prime} \mathrm{N}, 25^{\circ} 44.74^{\prime} \mathrm{E}$ & Dahlica & lichenella & & & 1 & \\
\hline \multirow[t]{2}{*}{ JP (Jylhänpera) } & $62^{\circ} 21.41^{\prime} \mathrm{N}, 25^{\circ} 42.65^{\prime} \mathrm{E}$ & Dahlica & charlottae & & & 1 & \\
\hline & & Dahlica & lazuri & & 2 & 5 & \\
\hline
\end{tabular}


TABLE S1 (continued).

\begin{tabular}{|c|c|c|c|c|c|c|c|}
\hline Sampling sites & Coordinates & Genus & Species & $\mathrm{L}$ & $\mathrm{F}$ & M & Other \\
\hline & & Dahlica & lichenella & & & 6 & \\
\hline & & Siederia & listerella & & & 2 & \\
\hline \multirow[t]{5}{*}{ JS (Jääskelä) } & $62^{\circ} 11.18^{\prime} \mathrm{N}, 25^{\circ} 52.62^{\prime} \mathrm{E}$ & Dahlica & charlottae & & 2 & & \\
\hline & & Dahlica & lichenella & & 1 & 4 & \\
\hline & & Siederia & listerella & & 3 & & \\
\hline & & Siederia & rupicolella & & & 1 & \\
\hline & & Dahlica & triquetrella & & 1 & & \\
\hline KN (Kanavuori) & $62^{\circ} 13.75^{\prime} \mathrm{N}, 25^{\circ} 54.3^{\prime} \mathrm{E}$ & Dahlica & fennicella & & 8 & & \\
\hline \multirow[t]{2}{*}{ KO } & $62^{\circ} 15.0^{\prime} \mathrm{N}, 25^{\circ} 39.2^{\prime} \mathrm{E}$ & Dahlica & charlottae & & & 1 & \\
\hline & & Dahlica & lichenella & & & 1 & \\
\hline KON (Konnevesi) & $62^{\circ} 39^{\prime} \mathrm{N}, 26^{\circ} 27^{\prime} \mathrm{E}$ & Dahlica & fennicella & & 3 & & \\
\hline $\mathrm{KT}$ & $62^{\circ} 13.11^{\prime} \mathrm{N}, 25^{\circ} 35.88^{\prime} \mathrm{E}$ & Siederia & rupicolella & & 2 & & \\
\hline \multirow[t]{2}{*}{ KU } & $62^{\circ} 12.72^{\prime} \mathrm{N}, 25^{\circ} 29.5^{\prime} \mathrm{E}$ & Siederia & listerella & & 1 & & \\
\hline & & Siederia & rupicolella & 1 & & & \\
\hline LO & $60^{\circ} 46.426^{\prime} \mathrm{N}, 23^{\circ} 0.444^{\prime} \mathrm{E}$ & Dahlica & triquetrella & & 3 & & \\
\hline LP (Leppalahti) & $62^{\circ} 13.61^{\prime} \mathrm{N}, 25^{\circ} 57.95^{\prime} \mathrm{E}$ & Dahlica & fennicella & & 4 & & \\
\hline \multirow[t]{2}{*}{ LV } & $62^{\circ} 15.55^{\prime} \mathrm{N}, 25^{\circ} 41.52^{\prime} \mathrm{E}$ & Dahlica & charlottae & & 1 & 1 & \\
\hline & & Dahlica & lichenella & & & 1 & \\
\hline MAYRA & $62^{\circ} 13^{\prime} \mathrm{N}, 25^{\circ} 40^{\prime} \mathrm{E}$ & Dahlica & lazuri & & & 1 & \\
\hline MK & $62^{\circ} 8.87^{\prime} \mathrm{N}, 25^{\circ} 34.14^{\prime} \mathrm{E}$ & Dahlica & charlottae & & & 1 & \\
\hline MM & $62^{\circ} 20.88^{\prime} \mathrm{N}, 25^{\circ} 42.08^{\prime} \mathrm{E}$ & Dahlica & lazuri & & 7 & 2 & \\
\hline \multirow[t]{2}{*}{ MS } & $62^{\circ} 5.58^{\prime} \mathrm{N}, 25^{\circ} 46.28^{\prime} \mathrm{E}$ & Dahlica & charlottae & & & 1 & \\
\hline & & Dahlica & lichenella & & 1 & 1 & \\
\hline MV & $62^{\circ} 4.94^{\prime} \mathrm{N}, 25^{\circ} 49.65^{\prime} \mathrm{E}$ & Dahlica & triquetrella & & 1 & & \\
\hline \multirow[t]{3}{*}{ MY } & $62^{\circ} 13.64^{\prime} \mathrm{N}, 25^{\circ} 41.77^{\prime} \mathrm{E}$ & Dahlica & lazuri & & 2 & 3 & \\
\hline & & Dahlica & lichenella & & & 1 & \\
\hline & & Siederia & listerella & & & 1 & \\
\hline \multirow[t]{2}{*}{ OV (Oravasaari) } & $62^{\circ} 11.48^{\prime} \mathrm{N}, 25^{\circ} 56.04^{\prime} \mathrm{E}$ & Dahlica & charlottae & & & 4 & \\
\hline & & Siederia & rupicolella & & 1 & & \\
\hline PAL & $62^{\circ} 17.423^{\prime} \mathrm{N}, 25^{\circ} 45.314^{\prime} \mathrm{E}$ & Siederia & listerella & & & 1 & \\
\hline \multirow[t]{2}{*}{ POT } & $62^{\circ} 13^{\prime} \mathrm{N}, 25^{\circ} 43^{\prime} \mathrm{E}$ & Dahlica & lazuri & & & 1 & \\
\hline & & Dahlica & lichenella & & & 3 & \\
\hline \multirow[t]{2}{*}{ RH } & $62^{\circ} 9.42^{\prime} \mathrm{N}, 25^{\circ} 33.7^{\prime} \mathrm{E}$ & Dahlica & lichenella & & 1 & & \\
\hline & & Siederia & rupicolella & & 1 & 1 & \\
\hline SIP (Sippulanniemi) & $62^{\circ} 11.99^{\prime} \mathrm{N}, 25^{\circ} 44.95^{\prime} \mathrm{E}$ & Dahlica & fennicella & & 4 & & \\
\hline SK & $62^{\circ} 7.57^{\prime} \mathrm{N}, 25^{\circ} 41.97^{\prime} \mathrm{E}$ & Dahlica & fennicella & & 1 & & \\
\hline SOLENOB & $62^{\circ} 13^{\prime} \mathrm{N}, 25^{\circ} 43^{\prime} \mathrm{E}$ & Siederia & listerella & & & 2 & \\
\hline \multirow[t]{2}{*}{ SV } & $62^{\circ} 6.78^{\prime} \mathrm{N}, 25^{\circ} 42.3^{\prime} \mathrm{E}$ & Dahlica & lazuri & & & 1 & \\
\hline & & Siederia & rupicolella & & 1 & 4 & \\
\hline \multirow[t]{2}{*}{ TOIV } & $62^{\circ} 34.114^{\prime} \mathrm{N}, 25^{\circ} 37.106^{\prime} \mathrm{E}$ & Dahlica & lichenella & & 1 & & \\
\hline & & Siederia & rupicolella & & & 1 & \\
\hline TOMMI & $62^{\circ} 13^{\prime} \mathrm{N}, 25^{\circ} 43^{\prime} \mathrm{E}$ & Siederia & listerella & & & 1 & \\
\hline \multirow[t]{3}{*}{ VK } & $62^{\circ} 10.15^{\prime} \mathrm{N}, 25^{\circ} 40.99^{\prime} \mathrm{E}$ & Dahlica & charlottae & & & 1 & \\
\hline & & Dahlica & lichenella & & 1 & & \\
\hline & & Siederia & rupicolella & & 1 & & \\
\hline TOTAL & & & & 6 & 119 & 70 & 1 \\
\hline
\end{tabular}

